\title{
Protein-crystal Interactions in Calcium Oxalate Kidney Stone Formation
}

\author{
Anuj Aggarwal ${ }^{1,2}$, Richard Tessadri ${ }^{3}$, Bernd Grohe ${ }^{1, *}$ \\ ${ }^{1}$ School of Dentistry, Schulich School of Medicine \& Dentistry, The University of Western Ontario, Canada \\ ${ }^{2}$ Biomedical Engineering Program, Faculty of Engineering, The University of Western Ontario, Canada \\ ${ }^{3}$ Institute for Mineralogy and Petrography, University of Innsbruck, Austria
}

Copyright $(\mathcal{C} 2015$ by authors, all rights reserved. Authors agree that this article remains permanently open access under the terms of the Creative Commons Attribution License 4.0 International License

\begin{abstract}
We have studied the ability of urinary molecules in altering the precipitation of kidney stone-related calcium oxalate monohydrate (COM) crystals and correlated the resulting morphologies with those of idiopathic COM kidney stones. We found that weakly acidic but highly glycosylated polyelectrolytes (Tamm Horsfall protein (THP), fetuinA, hyaluronic acid) do not significantly affect crystallization, and that THP and fetuinA show the tendency to aggregate in the presence of nascent crystals. It is proposed that highly glycosylated polyelectrolytes encapsulate nascent urinary crystals, prevent their aggregation, and thus act supportive in crystal excretion. Strong effects on crystallization were observed in the presence of the highly acidic molecules osteopontin (OPN), citrate, and the non-urinary glycosaminoglycans heparin and dextran sulfate. OPN formed non-structured concretions comparable with those found in the core of stones, while citrate formed platelets closely resembling crystal shapes found in the mantle region. However, it is unclear how the columnar growth in the mantle takes place. It is assumed that changing polyelectrolyte compilations/concentrations affect stone forming processes (e.g. equilibria, enhanced self-assembly), perhaps resulting in these structures. We have indeed shown that peptides can induce the formation of such structures. Moreover, heparin and dextran sulfate inhibited COM formation; implicating that these molecules could assist OPN, citrate but also THP in preventing stone formation.
\end{abstract}

Keywords Kidney Stones, Crystal Growth, Calcium Oxalate Monohydrate, COM, Protein-crystal Interaction, Osteopontin, Tamm Horsfall Protein, Fetuin A

\section{Introduction}

Stone-forming processes. The formation of idiopathic calcium oxalate stones is a complex process involving - besides nucleation and growth - the aggregation of calcium oxalate monohydrate (COM) crystals in an environment containing both promoters (e.g. membranes, other crystals) and inhibitors (e.g. citrate, urinary proteins, glycosaminoglycans (GAGs)) of these events [1]. In nearly all idiopathic stone formers, calcium oxalate $(\mathrm{CaOx})$ precipitation is induced at interstitial calcium phosphate (CaP) plaques, which serve as substrates for $\mathrm{COM}$ crystallization [2]. More specifically, these plaques (formed in hydroxyapatite (HA) saturated kidney tissue at $\mathrm{pH} \sim 7.4$ [2]) may extend to the urothelium and penetrate lesions [3], exposing the $\mathrm{CaP}$ to the more acidic urine ( $\mathrm{pH}$ 5.8-6.8 [1]) and, thus, providing sites for either a heterogeneous $\mathrm{COM}$ crystallization process [1-2] or a $\mathrm{CaP}-\mathrm{COM}$ mineral replacement reaction - a paradigm recently introduced by Sethmann et al. [4].

The next step of the stone-forming process results in the generation of the so-called core [5-6]. Its formation represents perhaps the most important stage in a COM calculus development. It has been suggested that the core-forming mechanism is based on the generation of a loose complex spatial structure composed of intergrown and twinned crystals within an organic matrix [1] starting on the nidus (COM-CaP plaques [2]). The increase in crystal number and volume results in a decreased expansion rate perpendicular to the perimeter of the growing concretion, a process which - in turn - leads to an increase of organic matter at the core boundary. It is assumed that the accumulation of organics at the boundary stops the core to grow and creates an interface on which columnar crystals can form, developing the stone's striated layer [5]. It is, however, poorly understood which mechanisms lead to the formation of multiple [7] or channel-like cores observed in some stones [8].

Similarly as for the core, Soehnle et al. [5] proposed a stop-and-go mechanism for the formation of the compact outer (mantle) region of the stone. They suggest that after the generation of first columnar crystals the radial layers gradually, but relatively fast, form until the increasing outer 
surface decreases the rate of the displacement perpendicular to the perimeter. At a certain development stage organic matter will completely cover the surface of the concretion, forming a layer which might be later one of the concentric rings. This layer may assist as a substrate (nucleator) for $\mathrm{COM}$ formation and the generation of a further striated stone section. A more complex process for the mantle's columnar crystal system is proposed by Al-Atar et al. [9], in which every domain (domain: columnar juxtaposed 'sheet-like' crystals) is formed by means of a continuous crystallization process periodically inhibited by organic matter so that alternating organic and polycrystalline layers appear. Thus, crystallization is initiated (forming new domains) or inhibited (stopping growth) depending on the presence of organic inhibitors Some studies show that these columnar crystals are partially interrupted by organic matter (every $\sim 100 \mu \mathrm{m}$ ) permeating through the entire striated layer and fill the space between adjacent columnar crystals [6]. Finally, all these interruptions form a regular macroscopic pattern around the stone, which is typical for the COM stones [7].

Polyelectrolytes involved in stone formation. Although exact physiological roles of the involved inhibitors are hard to predict, it was found that most of the inhibitory activity resides in citrate, glycosaminoglycans (GAGs) and in proteins such as Tamm-Horsfall protein (THP), osteopontin (OPN), urinary prothrombin fragment 1 (PTF1), and bikunin [1]. In addition, plasma proteins (e.g. albumin and $\mathrm{a}_{2} \mathrm{HS}$-glycoprotein (fetuinA)) appear to be involved into early stone-forming processes [1,10]. Besides some nucleators (e.g. lipids, membranes [1]), it is this combination of effectors which appears to control the driving forces of $\mathrm{CaOx}$ stone formation [1].

An important protein in preventing oxalate stone formation is the acidic and highly phosphorylated glycoprotein OPN [1]. In vitro studies have shown that the protein is a potent inhibitor of COM crystallization and aggregation [1], and promotes the formation of the less cell adherent calcium oxalate dihydrate [11]. It was concluded that the abundance of negatively charged carboxylic acid residues in combination with the protein's flexible backbone might play a primary role in mediating growth inhibition processes [12], in particular by interacting with the crystal edges and the $\mathrm{Ca}^{2+}$-rich $\{100\}$ face of COM crystals [13-14]. OPN is also one of the few proteins found to be incorporated into $\mathrm{CaOx}$ crystals and stones $[13,15-16]$. On the other hand, in vitro experiments in the presence of OPN [17] do not reveal $\mathrm{CaOx}$ growth patterns entirely comparable to those found in kidney stones $[16,18]$.

Of the low-molecular-weight inhibitors, negatively charged citrate appears to be the most significant [19]. It has been reported that it inhibits the nucleation and growth of COM crystals [1] by preferentially interacting with the $\mathrm{Ca}^{2+}$-rich $\{100\}$ face [20]. The specificity of citrate to the $\{100\}$ face results in the formation of plate-like crystals [20], which, if they would grow columnar, very closely resemble the crystal assemblies in the mantle region.
Two other proteins, the Tamm-Horsfall protein (THP) and fetuinA are highly glycosylated [21-22]. While THP is the most abundant urinary protein produced in the kidney $(\sim 100$ $\mathrm{mg} /$ day) [21], concentration levels of fetuinA (actually a serum protein) mainly increase in disease such nephrolithiasis [23]. It has been reported that both proteins inhibit the agglomeration of crystals $[1,23]$. However, they are also subject of controversial findings. For instance, THP is thought to play an important role in regulating stone formation by inhibiting crystal aggregation [24], while some have suggested that the protein can promote $\mathrm{CaOx}$ and kidney stone formation [25]. With respect to fetuinA, not much is known about its effect on $\mathrm{CaOx}$ crystal or stone formation $[18,23]$. However, it was found that the protein binds to small hydroxyapatite particles and forms dispersions [26]. Thus, fetuinA might act in urine in a similar way by enclosing nascent crystals to prevent COM from aggregating.

Glycosaminoglycans (keratan sulfate, heparan sulfate, dermatan sulfate, hyaluronic acid, chondroitin-6-sulfate and chondroitin-4-sulfate) are major components of the urinary tract [1]. In vitro studies have shown that the strongest inhibitor of $\mathrm{CaOx}$ formation among the GAGS is heparan sulfate, while chondroitin sulfate, the most abundant urinary GAG, indicated no effect [27]. Ryall and coworkers [28] have reported that from all investigated urinary GAGs only heparan sulfate was detected in the organic matrix of $\mathrm{CaOx}$ crystals. However, its presence in stones was only marginal [27]. Moreover, Michelacci et al. [29] have shown that total urinary GAG concentrations of stone formers are reduced to a level of $\sim 33 \%$, with no evidence that concentrations of specific GAGs have been lowered more than others [29]. This outcome implies (a) that lower GAG concentrations in stone formers are not necessarily correlated with higher incorporation rates of individual GAGs into stone matrices, and (b) that GAGs might act as dispersants preventing crystal aggregation and help to remove crystals more easily with the urine. The latter process is supported by observations of Lieske et al. [30] who have recently reported that GAGs (including the non-urinary GAG heparin [31]) inhibit adhesion of crystals to cell walls by coating the crystals.

The present study. In the present study we have investigated citrate/protein/GAG-crystal interactions and compared the resulting crystal habits etc. with morphologies and structures observed in idiopathic COM kidney stones. The findings suggest that first stages of stone formation (onset of core formation) are largely affected by a wide spectrum of proteins (mainly OPN), GAGs, peptides etc., while later stages of the stone development appear to be primarily altered by citrate (less by OPN; perhaps by acidic peptides). Moreover, we found that heparin and/or low molecular weight dextran sulfates might be (1) potent effectors/agents to assist OPN in COM modulation, and (2) excellent dispersants of small (just nucleating) COM crystals, supportive in pathologies where e.g. THP is not fully functioning. 


\section{Materials and Methods}

\subsection{Kidney Stones and Their Analysis}

Kidney stones. The Ethics Board for the Review of Health Sciences Research (The University of Western Ontario Research) involving Human Subjects approved the studies. All stone samples used are 15-20 years old; the patients are unknown.

Eight $\mathrm{CaOx}$ stones (dimensions: 12 - $17 \mathrm{~mm}$ ) were used for the present investigation. The stones were broken up in parts and fragments (not larger than $10 \mathrm{~mm}$ ) of seven stones were selected, based on XRD analysis. To this end, a small part of each fragment was scraped away and crushed for powder diffractometry (see below). Stones that showed only COM peaks (Whewellite; a conservative estimate would put the presence of other phases at less than 5\%) were selected for further analysis. One stone indicated high ratios of Weddellite (calcium oxalate dihydrate; COD) and was not used for the present study.

Optical microscopy. Kidney stones were imaged using a Nikon (SMZ, 1500) microscope to determine the outer structure, the surface texture and other features of stones.

Scanning electron microscopy (SEM). Scanning electron microscopy (LEO, 1540XB, Carl Zeiss, Jena, Germany) was employed to determine the morphology and compactness of stone masses, the surface structure of stone matrices, the surface structure and habit (shape, dimensions, assembly) of formed aggregates as well as crystal phases. To this end, stone fragments (some large fragments were divided again) were fixed on a mount, coated with osmium ( 4 nm thickness; Plasma Coater OPC-80T) and investigated using an acceleration voltage of $3 \mathrm{kV}$ and a working distance between 5 and $9 \mathrm{~mm}$. For backscatter electron microscopy an acceleration voltage of $15 \mathrm{kV}$ and a working distance between 9 and $11 \mathrm{~mm}$ was used.

Energy dispersive X-ray analysis (EDX). The chemical composition of stones was analyzed in several different spots of each sample (coated with osmium, $\sim 4 \mathrm{~nm}$ thickness; Plasma Coater OPC-80T) using EDX (Oxford INCA Instruments) at an acceleration voltage of $20 \mathrm{kV}$ (penetration depth, $\sim 2 \mu \mathrm{m}$ ). At least three randomly chosen spots in particular regions (core or mantle or surface) and in various regions of a stone fragment were analyzed, respectively, and the elementary composition determined. Evaluation of the inorganic and organic content of stone regions was accomplished by determining the fractions (in wt.\%) of calcium phosphate and calcium oxalate minerals (via the stoichiometry of hydroxyapatite [HA, $\left.\mathrm{Ca}_{5}\left(\mathrm{PO}_{4}\right)_{3} \mathrm{OH}\right]$ and Whewellite $\left[\mathrm{COM}, \mathrm{CaC}_{2} \mathrm{O}_{4} \cdot \mathrm{H}_{2} \mathrm{O}\right]$ ), followed by calculation of the organic content (based on carbon, oxygen). Other elements, such as $\mathrm{Na}, \mathrm{Cl}, \mathrm{K}, \mathrm{Mg}$, were considered as salts (e.g. $\mathrm{NaCl}, \mathrm{KCl}$ ) or as trace compounds such as Al- and Zn oxides. As the stones were coated with Os for SEM the Os-content had to be taken into account as well.
X-ray powder diffraction (XRD). Crystal structure analysis of kidney stone powders ( $20 \mathrm{mg}$ on glass slides) were carried out using a Bruker-D8-advance powder diffractometer $(\mathrm{Cu} \mathrm{K \alpha}[\lambda=0.1506 \mathrm{~nm}], 40 \mathrm{kV}, 40 \mathrm{~mA})$. Spectra were collected in the $\theta / 2 \theta$ range between 2 and $40^{\circ}$, using a step size of $0.01^{\circ}$ measuring $2 \mathrm{~s}$ per step. Evaluation: Bruker-AXS/Germany (Eva-version 19.0.0.0/1996-2113 and PDF-4-2013; ICDD, USA).

\subsection{Analysis of in Vitro Crystallization and Adsorption}

Chemicals and crystallization in the presence of effectors. Crystallization of $\mathrm{CaOx}$ was initiated using the method previously described [32-33]. Final concentrations were $1 \mathrm{mM}$ calcium nitrate, $1 \mathrm{mM}$ sodium oxalate, $10 \mathrm{mM}$ sodium acetate, and $150 \mathrm{mM}$ sodium chloride. The total volume was $1 \mathrm{ml}$ using culture plates. Precipitation of $\mathrm{CaOx}$ occurred on mica disks and either in the presence or in the absence of THP ( $~ 85 \mathrm{kDa}$; human; Chemicon International Inc. CA, USA), fetuinA ( $\sim 50 \mathrm{kDa}$; bovine; used after isolation (see Heiss et al.[26]) from a commercial preparation; Sigma-Aldrich), OPN ( 37.5 kDa; rat bone; isolated and purified via established methods), citrate (trisodium citrate dehydrate, $\mathrm{M}_{\mathrm{W}} 294.1 \mathrm{~g} / \mathrm{mol}$; Sigma-Aldrich), and the GAGs heparin (HEP, $\sim 15 \mathrm{kDa}$; porcine intestinal mucosa; Sigma-Aldrich), hyaluronic acid (Hya; 70-100 kDa; bovine - vitreous humor; Worthington Bioch. Corp. New York) and dextran sulfate (5 kDa (DS5) or 100 kDa (DS100); leuconostoc spp.; BioChimica Fluka \& Sigma-Aldrich). To this end, aqueous stock solutions of 50 $\mu \mathrm{g} / \mathrm{ml}$ protein or glycosaminoglycan and a $5 \mathrm{mM}$ citrate solution were prepared. All effector concentrations used in this study were kept under or near physiological concentrations (see e.g. [33]). The majority of the experiments were carried out at a reaction time of $30 \mathrm{~min}$. A series of experiments was performed by varying the reaction time between 30 and $1440 \mathrm{~min}$.

Microscopy, imaging and data processing. Precipitates were studied by SEM (LEO 1540XB, Carl Zeiss, Germany) without metal coating, using an acceleration voltage of $1 \mathrm{kV}$ and a working distance of $3.5 \mathrm{~mm}$. Crystal shapes (habits), morphologies and phases were evaluated as previously described [33]. To calculate precipitated volumes, COM and COD crystals were identified, counted and dimensions measured from SEM micrographs as previously described [33]. The individual mean values ( \pm standard deviation) were determined from 6 to 9 microscopic fields (2-3 from each sample) per calculated volume, with between 50 and 350 crystals per microscopic field. To test if sample values were significantly different from corresponding controls, one-way ANOVA and Dunnett's multiple comparison tests were carried out as previously described [33]. To correlate crystallization results with specific properties of polyelectrolytes, physicochemical characteristics (isoelectric points (pI), net charges and the hydrophilicity) were determined as previously described [33]. 
Analysis of protein adsorption to preformed COM crystals. Labeling of THP and fetuinA with Alexa Fluor 488 , growth of COM crystals and confocal microscopy were performed as previously described [32]. In brief, $200-\mu \mathrm{l}$ aliquots of solutions containing $1 \mathrm{mM}$ calcium nitrate, $1 \mathrm{mM}$ sodium oxalate, $10 \mathrm{mM}$ sodium acetate and $150 \mathrm{mM}$ sodium chloride were added to glass-bottomed Petri dishes. After incubation at room temperature for $3 \mathrm{~h}$ (to pre-grown crystals), the dishes were placed on the heated $\left(37 \pm 0.2^{\circ} \mathrm{C}\right)$ stage of a Zeiss LSM 410 confocal microscope and $20-\mu \mathrm{l}$ aliquots of a $1 \mu \mathrm{g} / \mathrm{ml}$ solution of labeled THP or fetuinA added to the solution. After $60 \mathrm{~min}$. of residence time crystals and the fluorochrome were imaged using a HeNe laser $(\lambda=632.8 \mathrm{~nm})$ and a $\mathrm{KrAr}$ laser $(\lambda=488 \mathrm{~nm})$, respectively [32]. To this end, optical sections of crystals/fluorochrome (nucleated from $\{100\}$ faces) were taken every $0.5 \mu \mathrm{m}$ along the microscopic $\mathrm{z}$ axis starting from crystal-glass interface and ending at/near the crystal-solution interface. To gain more contrast some green false color images were converted to gray scale.

\section{Results and Discussion}

\subsection{Morphologies and Formed Structures of Papillary Stones (Revisited)}

Optical microscopy (Figure 1a,b) of idiopathic Whewellite stones (X-ray diffraction revealed the presence of Whewellite, other phases were not detected; Figure 2) shows morphologies typical for papillary calculi of mostly idiopathic origin [2]. The surface of these stones is not smooth; rather indicating intergrown globules (Figure 1b), with an inner structure more open than the outer region (Figure 1a).

Using SEM, we analyzed these regions of stones in more detail. Figure $1 \mathrm{c}, \mathrm{d}$ shows cross sections of stone fragments. The inner region (the core) features fine and open structures of layered platelets, partly forming dumbbell or rosette-like shapes (Figure 3a-c); or it shows coarser structures but still indicating platelets, which locally form dumbbells or rosettes (Figure 3d,e). Some of these structures are covered by net-like coatings (Figure 3e). The shapes found are not unusual [18] and can be observed in urine [34], in in vitro studies [17] and in precipitates of inorganic solutions [13-14,32], as well.

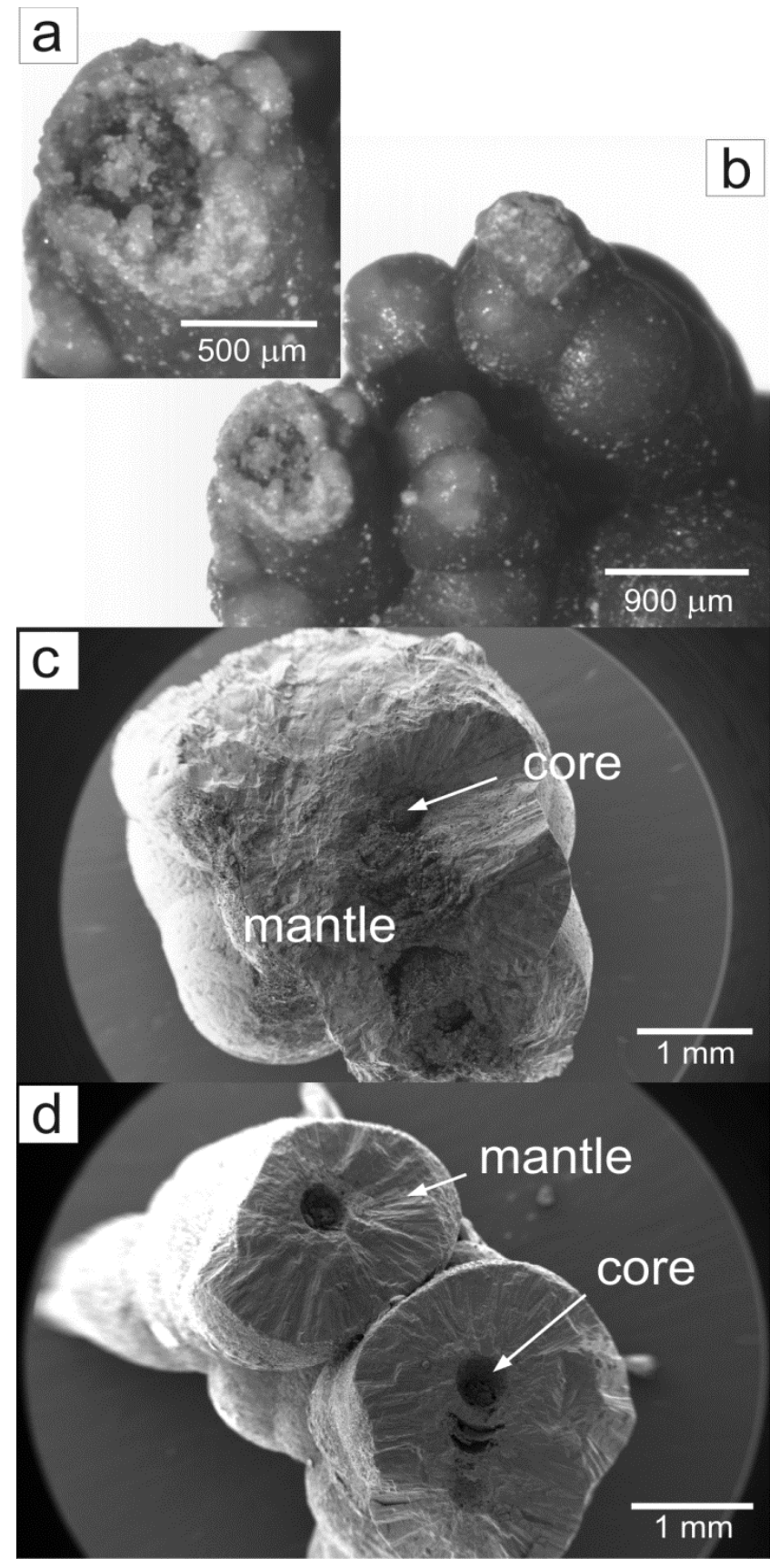

Figure 1. Optical $(a, b)$ and scanning electron microscopy $(c, d)$ of cross-sectioned Whewellite stone fragments. Note: the inner structure [(a) is an enlarged section of (b)] is more open than the outer region. SEM micrographs also show morphologically differences between the inner (core) and the outer region (mantle) of such stones. 


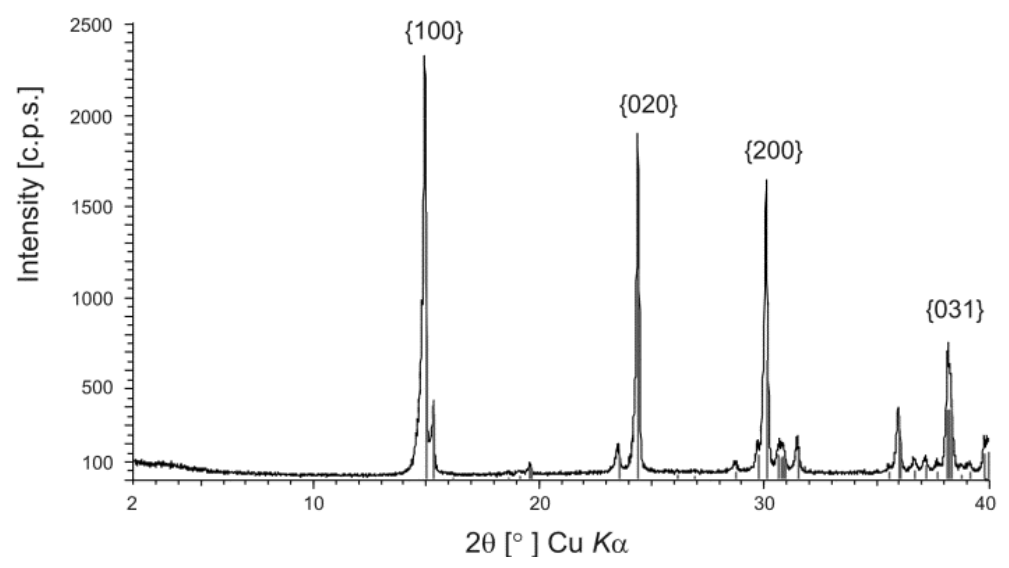

Figure 2. Representative powder diffraction pattern of powders investigated. The spectrum obtained is consistent with Whewellite (grey lines, monoclinic calcium oxalate monohydrate with the space group P2 1 /c; Tazzoli \& Domeneghetti, Am. Mineral. 1980, 65, 327).

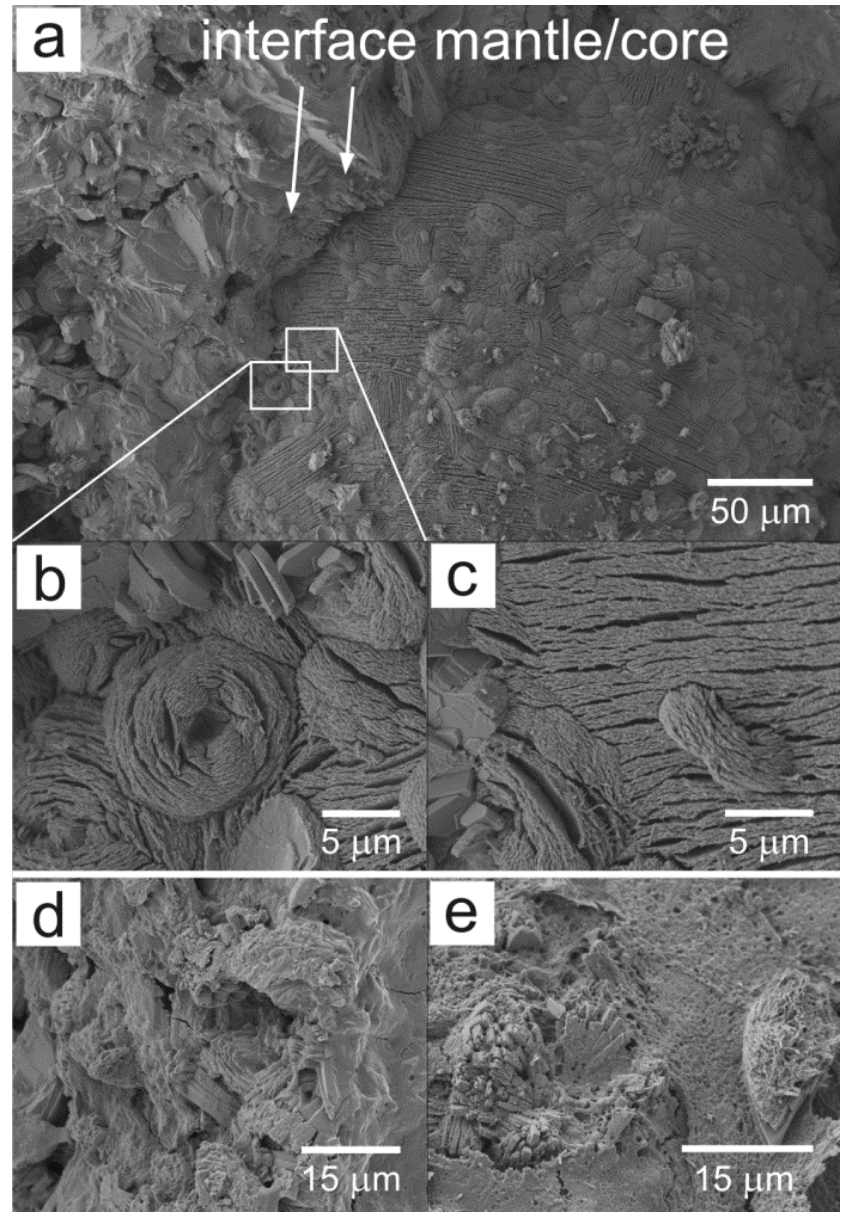

Figure 3. Scans (SEM) of inner regions of stones. (a) Core/mantle interface with core features (b) rosette-like and (c) dumbbell-like shapes. Some core structures are (d) coarser and/or show (e) net-like coatings.

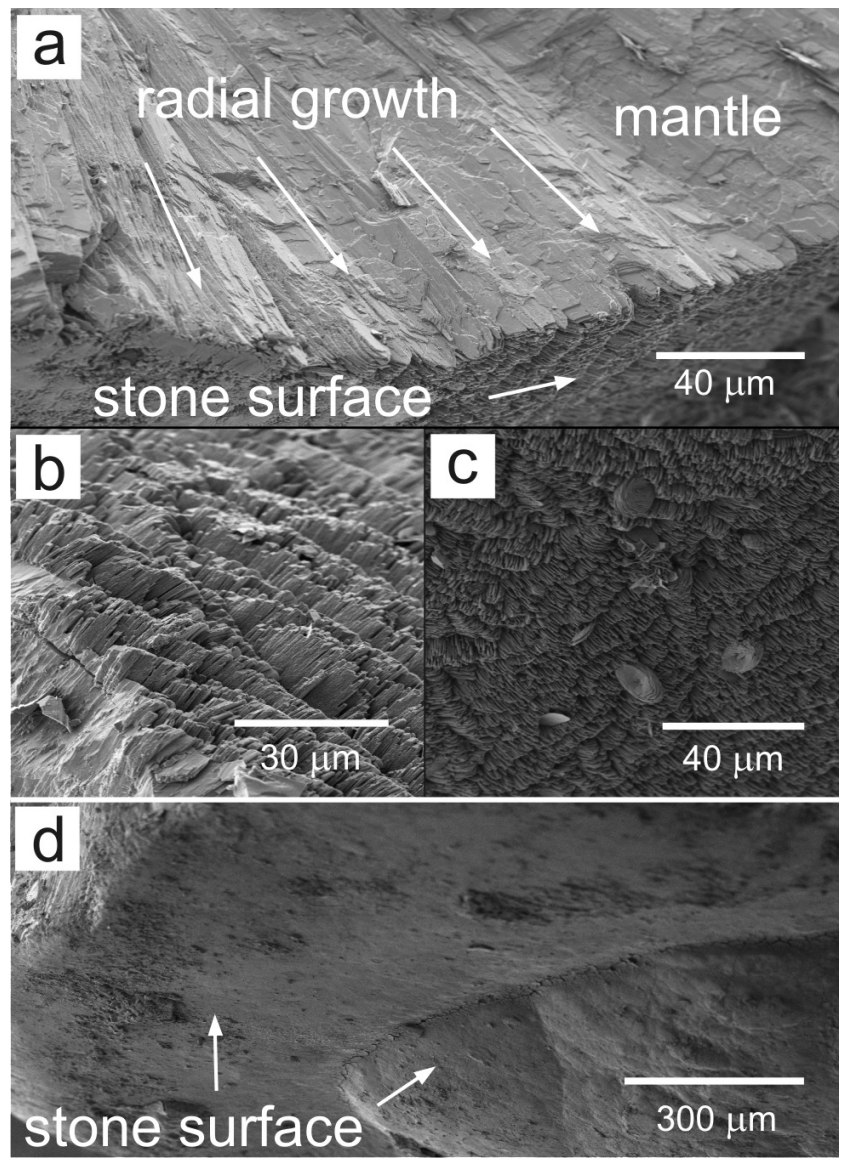

Figure 4. SEM micrographs of stone surfaces. (a) Mantle region. Note the radial growth and the stone surface. (b) Layered crystals and (c) locally formed/attached rosette-like crystals. (d) Some surfaces indicate overgrowth or coating (perhaps proteins, tissue fragments, cells etc.). 
The morphological transition from the core to the neighbor region of the stone is relatively sharp and recognizable by differences in material porosity and compactness (Fig 1c,d and 3a). This region (the mantle) consists of a compact mass, which shows a radial structured orientation of layered plate-like grown crystals (see e.g. Figure 1d and 4a).

Local inclusions of compacted and multidirectional grown crystals can be found (e.g. Fig 1c, left part of the stone). However, we found no sign of the presence of concentrically laminated peripheral layers, as reported by Grases, McKee and coworkers [7,18], a finding perhaps based on the analysis method used.

The outer surface of these stones shows some growth-regularities, which are similar to those of the mantle (compare Figure 4a-c with Figure 1). It appears, however, that the stone surfaces are primarily affected by the stone's surrounding environment. The surface can be smooth or rough, indicating - in some cases - an overgrowth or coating by urinary compounds (perhaps composed of a mixture of proteins, tissue fragments etc.; Figure 4d) or it shows a high density of layered and well ordered crystals (Figure 4a-c).
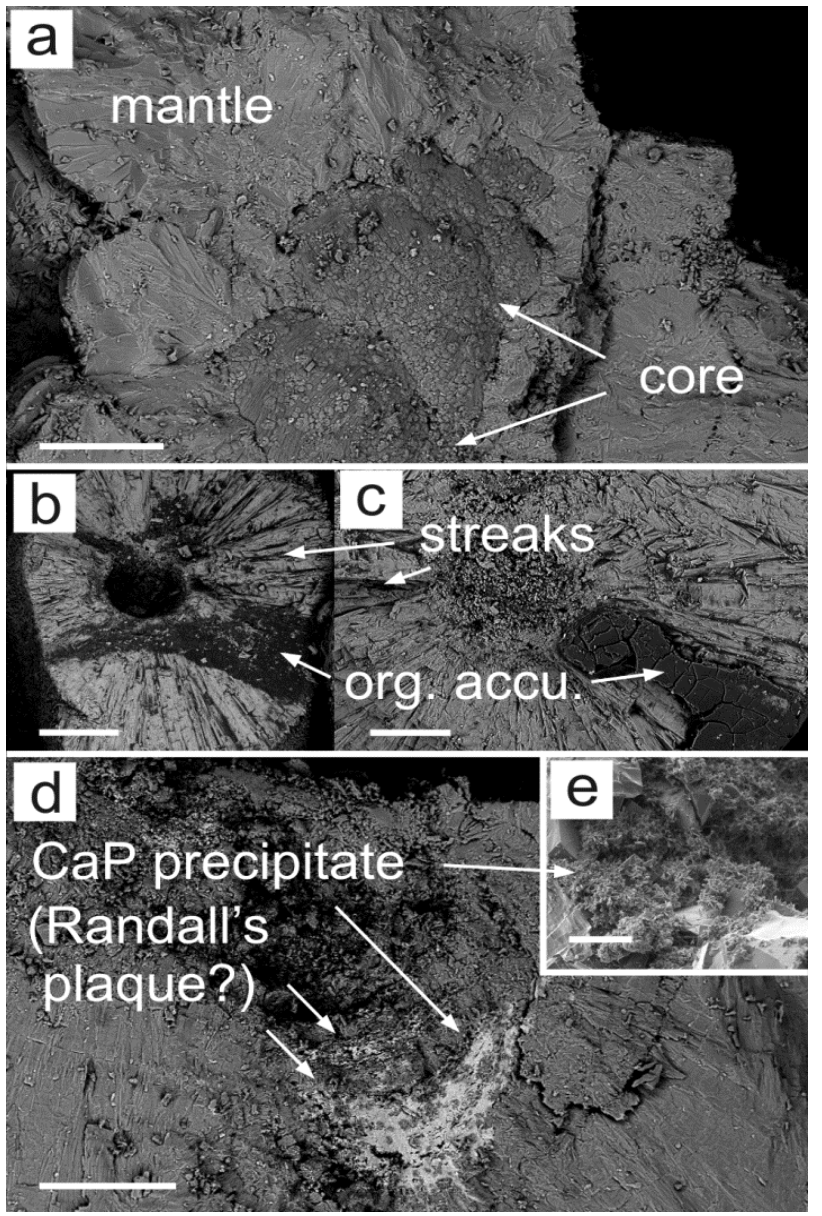

Figure 5. Backscatter electron microscopy of stone regions. (a) Cross section through a stone showing a core being darker and more organic-rich than the mantle. Panels (b) and (c) show dark streaks within the mantle (parallel to radial grown crystals) and large organic accumulations (see: org. accu.). In (d) and (e) very bright areas indicate highly crystalline material (EDX for this region reveals significant amounts of calcium and phosphate; see text and Table 1). Scale bars: a,c,d: $200 \mu \mathrm{m}$; b: $400 \mu \mathrm{m}$; e: $20 \mu \mathrm{m}$.
By combining backscatter electron microscopy (BS-SEM) with energy dispersive analysis (EDX), we were able to differentiate between low-dense material (darker contrast [35]) containing higher ratios of organics and high-dense material (brighter contrast [35]), which is more inorganic and crystalline. For instance, core regions (Fig 5a) indicate less dense and more organic material (organics: 10.29 wt.\% \pm 1.91 ; see Table 1) than the mantle (Fig 5a; more dense/inorganic, organics: $0.47 \mathrm{wt} . \% \pm 0.16)$, a finding also confirming results by Cheng et al. [36].

But within mantle regions, sections can be pervaded by organic (dark) streaks oriented parallel and perpendicular to the radial orientation of plate-like grown crystals (Figure $5 \mathrm{~b}, \mathrm{c})$, or they can be displaced by large accumulations of organic material (organics: 67.99 wt.\% $\%$ 12.39), which might be supply/drainage systems for urinary compounds (Figure $5 \mathrm{~b}, \mathrm{c}$ ). On the other hand, there are also highly dense (bright) areas found within the mantle (Figure 5d). EDX of these areas revealed inorganics of around $85.10 \mathrm{wt} . \% \pm 7.40$, of which $\sim 62$ wt. $\%$ is $\mathrm{CaP}$. These $\mathrm{CaP}$ values are pretty high compared to other mantle regions ( $\mathrm{CaP}: 0-2$ wt.\%). In addition, these areas are also rich in organic matrix phase (14.10 wt. $\% \pm 5.15)$, suggesting the presence of Randall's plaque [2-3].

\subsection{The Origin of Morphology and Structure Variations in Stones: The Effects of Polyelectrolytes on $\mathrm{CaOx}$ Precipitation}

Recently, we have investigated a variety of urinary proteins (e.g. OPN, albumin, bikunin, PTF1) with respect to their ability to affect $\mathrm{CaOx}$ crystallization and, consequently, $\mathrm{CaOx}$ stone formation [33]. The present work complements the number of urinary macromolecules used by studying GAGs (e.g. hyaluronic acid), revisiting some proteins (e.g. THP, fetuinA) and analyze long-time crystallization experiments in the presence of OPN and citrate.

Effects of THP, fetuin $A$ and some glycosaminoglycans. The precipitation behavior of $\mathrm{CaOx}$ in the presence of THP, fetuinA, hyaluronic acid (Hya), heparin (HEP) and two synthetic dextran sulfates (low (DS5) and high (DS100) molecular weight) is shown in Figure 6.

Adding $10 \mu \mathrm{g} / \mathrm{ml}$ polyelectrolyte, only heparin and the dextrans lead to a significant decrease in precipitated COM volume (Figure 6a). However, Figure 6e-h shows that all GAGs induce morphological changes of COM crystals. With respect to COD, all GAGs increase the crystallization of the dihydrate phase (Figure 6a). It is obvious that this reaction takes place via a dose-response-relationship (inhibition of COM results in precipitation of COD) and that the increase in net negative charges (from hyaluronic acid to dextran sulfate, see Table 2) might result in this reaction profile. Recent investigations suggest that highly negative charged polyelectrolytes adsorb to just forming positively charged COM crystals $[37,38]$ and block the incorporation of calcium and oxalate ions into COM crystal lattices [39-41]. However, this obstruction to reduce the supersaturation will drive - in turn - the precipitation of the thermodynamically less stable COD phase [42]. 
Table 1. Evaluation of the inorganic/organic composition of different stone regions.

\begin{tabular}{cccccc}
\hline Stone region & $\mathrm{CaP}^{\#}[\mathrm{wt. \%}$ ] & $\mathrm{COM}^{\$}$ [wt.\%] & Inorganics * [wt.\%] & Organics ${ }^{\circledR}$ [wt.\%] & $\begin{array}{c}\text { Total }^{\&} \text { composition } \\
\text { [wt.\%] }\end{array}$ \\
\hline Core & $0.77 \pm 0.24$ & $85.16 \pm 0.37$ & $87.69 \pm 2.35$ & $10.29 \pm 1.91$ & $97.98 \pm 0.44$ \\
Mantle & $1.14 \pm 0.46$ & $82.01 \pm 10.10$ & $98.93 \pm 0.65$ & $0.47 \pm 0.16$ & $99.40 \pm 0.51$ \\
Org. troughs & $1.18 \pm 1.67$ & $26.02 \pm 12.84$ & $27.92 \pm 13.49$ & $67.99 \pm 12.39$ & $95.90 \pm 1.09$ \\
CaP areas & $62.56 \pm 9.48$ & $22.54 \pm 3.38$ & $85.10 \pm 7.40$ & $14.10 \pm 5.16$ & $99.20 \pm 0.23$ \\
\hline
\end{tabular}

\# Based on the stoichiometry of hydroxyapatite (most common CaP phase $\left.{ }^{2}\right) ;{ }^{\$}$ based on the stoichiometry of calcium oxalate monohydrate; * Oxides, chlorides (e.g. NaCl, $\left.\mathrm{KCl}, \mathrm{MgO}, \mathrm{Al}_{2} \mathrm{O}_{3} \mathrm{ZnO}\right) ;{ }^{\circledR}$ Amino acids (C-H-N), carbohydrates (C-H-O), sulfur compounds (C-H-S); ${ }^{*}$ some measured elements $(\mathrm{Fe}$, $\mathrm{F}$, Si etc.) are not in the calculations.
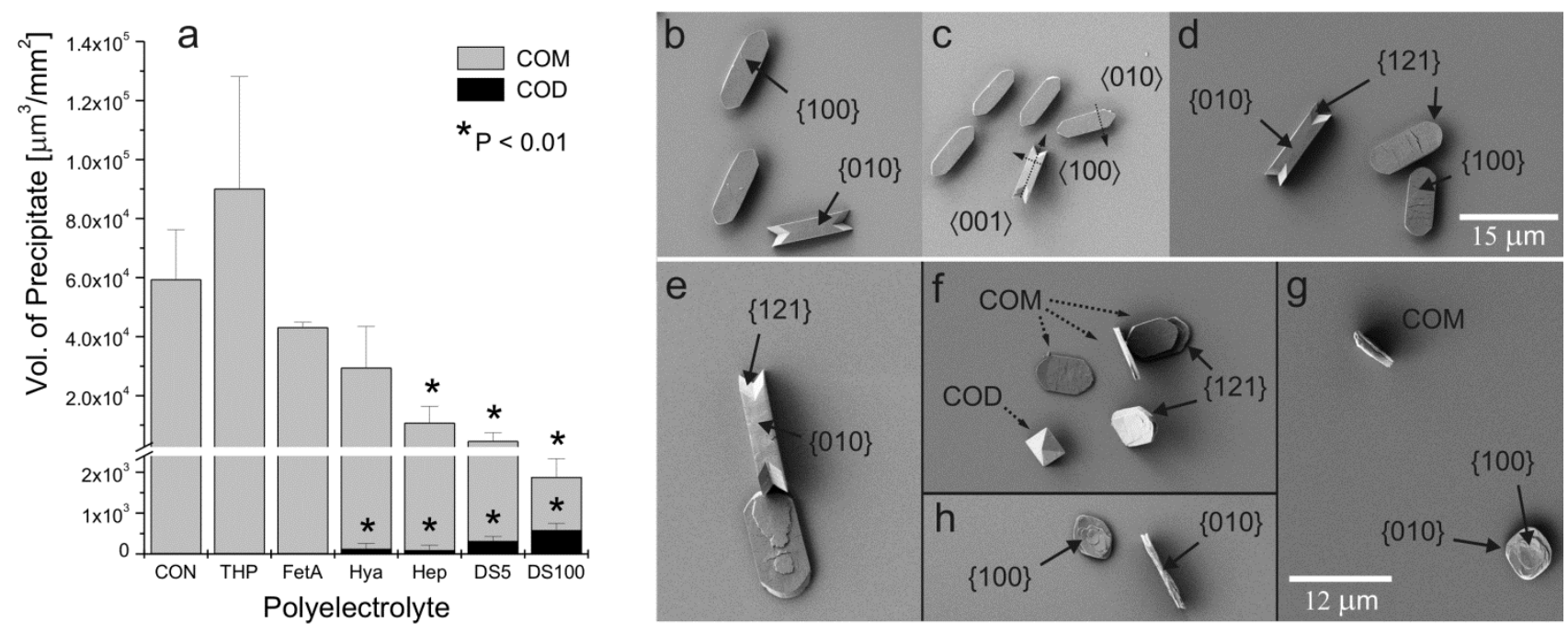

Figure 6. Crystallization of $\mathrm{CaOx}$ crystals in the presence of glycoproteins (THP, fetuinA) and glycosaminoglycans (Hya, HEP, DS5, DS100). (a) Crystallized volume of COM and COD $\left(\left[\mathrm{Ca}^{2+}\right]=\left[\mathrm{C}_{2} \mathrm{O}_{4}{ }^{2-}\right]=1 \mathrm{mM}\right.$; for $\left.30 \mathrm{~min}\right)$ in the absence and presence of $10 \mu \mathrm{g} / \mathrm{ml}$ polyelectrolyte. *P $<0.01-$ significantly different from the corresponding control (calculated using Dunnett's multiple comparison tests). (b-h) SEM of COM and COD grown under (b) control conditions (no effector added) and in the presence of $10 \mu \mathrm{g} / \mathrm{ml}$ (c) THP, (d) fetuinA, (e) Hya, (f) HEP, (g) DS5 (5 kDa) and (h) DS100 (100 kDa). The scale bar in (d) also applies to panels (b) and (c); the scale bar in (g) also applies to panels (e), (f) and (h).

In contrast, THP and fetuinA show no significant effect on precipitated COM and COD volumes (Figure 6a). It appears, however, that THP promotes COM precipitation. Figure 6c shows that crystals grown in the presence of THP are smaller (without indicating any effect on morphologies) than those of controls, suggesting that $\mathrm{COM}$ nucleation rates are increased by THP rather than growth rates. FetuinA, on the other hand, slightly affects COM growth by causing the formation of rounded $\{100\} /\{121\}$-edges at both ends of the crystals (Figure 6d), but with no measurable impact on the precipitated COM volume (Figure 6a). Both THP and fetuinA have low net negative charges (see Table 2), perhaps the reason why these proteins are not really significant in affecting COM and COD precipitation. To get more insight into protein-crystal interactions of THP and fetuinA we Alexa-488-labeled the proteins and studied their adsorption behavior to COM crystals, using confocal microscopy. However, both proteins show aggregation and sedimentation rather than adsorption to crystals (see Fig. 7). A similar outcome was recently found for bikunin, which was studied under the same conditions [33]. But the very same study also shows that albumin and PTF1 develop distinct adsorption profiles, even though these proteins indicate similarly low net negative-charge properties as bikunin, THP or fetuinA (see Table 2). So far, it is unclear why aggregation occurs at all. All proteins used in the present study are intact, not missing e.g. sialic acids important for the functioning of THP or fetuinA [26,43-44] 
Table 2. Properties and characteristics of proteins, glycosaminoglycans and other polyelectrolytes relevant in the present work

\begin{tabular}{|c|c|c|c|c|c|c|c|}
\hline Effector & $\mathrm{M}_{\mathrm{W}}[\mathrm{g} / \mathrm{mol}]$ & $\mathrm{pI}[\mathrm{pH}]$ & $\begin{array}{c}\text { Norm. } \mathrm{NC}^{\mathrm{A}} \\
\text { at } \mathrm{pH} \\
6.75\end{array}$ & $\begin{array}{r}\text { Norm. HP }{ }^{B} \\
{[\mathrm{~kJ} / \mathrm{mol}]}\end{array}$ & $\begin{array}{l}\text { Effect on COM } \\
\text { AdP/EoN/EoG }\end{array}$ & $\begin{array}{c}\text { Vol. COM } \\
{\left[\begin{array}{c}\left.\mathrm{m}^{3} / \mathrm{mm}^{2}\right] \\
\cdot 10^{3}\end{array}\right.}\end{array}$ & $\begin{array}{c}\text { Vol. COD } \\
{\left[\mu \mathrm{m}^{3} / \mathrm{mm}^{2}\right]} \\
\cdot 10^{3}\end{array}$ \\
\hline control & -- & -- & -- & -- & -- & $59.5 \pm 16.8^{\mathrm{D}}$ & $0^{\mathrm{D}}$ \\
\hline citrate & 294.1 & $\mathrm{n} / \mathrm{a}$ & $\mathrm{n} / \mathrm{a}$ & $\mathrm{n} / \mathrm{a}$ & $(\mathrm{n} \cdot \mathrm{m} / \mathrm{y} / \mathrm{y})^{\mathrm{E}}$ & $0.24 \pm 0.15^{\mathrm{E}^{*}}$ & $0^{\mathrm{E \#}}$ \\
\hline bikunin & $\sim 41,000^{\mathrm{H}}$ & $5.95^{\mathrm{I}}$ & -0.21 & 3.04 & $\left(n^{\mathrm{G}} / \mathrm{y} / \mathrm{n}\right)^{\mathrm{D}}$ & $110.9 \pm 20.7^{\mathrm{D}^{*}}$ & $0^{\mathrm{D} \#}$ \\
\hline HSA & $\sim 66,500^{\mathrm{I}}$ & $5.67^{\mathrm{I}}$ & -0.16 & 9.31 & $(\mathrm{y} / \sim / \sim)^{\mathrm{D}}$ & $71.9 \pm 80.5^{\mathrm{D \#}}$ & $0.05 \pm 0.02^{\mathrm{D} \#}$ \\
\hline PTF1 & $\sim 31,000^{\mathrm{J}}$ & $3.58^{\mathrm{K}}$ & -0.62 & 7.98 & $(\mathrm{y} / \sim / \sim)^{\mathrm{D}}$ & $84.9 \pm 11.8^{\mathrm{D} \#}$ & $0.02 \pm 0.01$ \\
\hline fetuinA & $\sim 50,000^{\mathrm{L}}$ & $3.3^{\mathrm{M}}$ & -0.39 & 1.35 & $\left(\mathrm{n}^{\mathrm{G}} / \mathrm{n} / \sim\right)^{\mathrm{PW}}$ & present work & present work \\
\hline THP & $\sim 85,000^{\mathrm{N}}$ & $3.5^{\mathrm{N}}$ & -0.42 & 1.13 & $\left(\mathrm{n}^{\mathrm{G}} / \mathrm{y} / \mathrm{n}\right)^{\mathrm{PW}}$ & present work & present work \\
\hline kOPN (hum.) & $37,700^{\circ}$ & $4.1^{\mathrm{A}}$ & -1.56 & 27.08 & $(y / y / y)^{F}$ & $0.2 \pm 0.1^{\mathrm{F}^{*}}$ & $32.5 \pm 31.1^{\mathrm{F}^{*}}$ \\
\hline bOPN (rat) & $37,622^{P}$ & $4.00^{\mathrm{Q}}$ & -1.68 & 28.25 & $(y / y / y)^{D}$ & $4.4 \pm 0.4^{\mathrm{D}^{*}}$ & $32.9 \pm 7.1^{\mathrm{D}^{*}}$ \\
\hline HA & $\sim 70,000^{\mathrm{R}}$ & $2.08^{\mathrm{A}}$ & -2.62 & 32.86 & $(\text { n.m. } / \mathrm{n} / \mathrm{y})^{\mathrm{PW}}$ & present work & present work \\
\hline HEP & $\sim 15,000^{\mathrm{R}}$ & $2.31^{\mathrm{A}}$ & -6.77 & 85.37 & (n.m. / / y) ${ }^{\mathbf{P W}}$ & present work & present work \\
\hline DS 5 & $5,000^{\mathrm{R}}$ & $2.64^{\mathrm{A}}$ & -8.38 & 105.46 & (n.m. / y / y) ${ }^{\mathbf{P W}}$ & present work & present work \\
\hline DS 100 & $100,000^{\mathrm{R}}$ & $1.38^{\mathrm{A}}$ & -10.36 & 130.69 & (n.m. / y / y) ${ }^{\mathbf{P W}}$ & present work & present work \\
\hline
\end{tabular}

$\mathbf{M}_{\mathbf{W}}$ : molecular mass; $\mathbf{P I}$ : isoelectric point; norm NC: net charge (normalized: value per $1 \mathrm{kDa}$ ); ${ }^{\mathrm{A}}$ Calculated value, http://ca.expasy.org (different tools); norm HP: hydrophilicity (normalized: value per $1 \mathrm{kDa}$ ); ${ }^{\mathrm{C}}$ Calculated values based on an empirical hydrophilicity scale (Hopp \& Woods, PNAS 1981, 78, 3824-3828; Grohe et al., Langmuir 2009, 25, 11635-11646.); AdP/EoN/EoG: adsorption profile / effect on nucleation / effect on growth (y: yes, n: no, : slightly, n.m.: not measured); Vol. COM or COD: total volume of precipitated COM or COD in the presence of $10 \mu \mathrm{g} / \mathrm{ml}$ polyelectrolyte or $250 \mu \mathrm{M}$ citrate;
${ }^{\mathrm{P}} \mathrm{P}<0.01$ - significantly different from corresponding control, ${ }^{\#} \mathrm{P}>0.05$, not significant (calculated by Dunnett's multiple comparison test); ${ }^{\mathrm{PW}}$ present work; ${ }^{\mathrm{D}}$ recent work: precipitated within $30 \mathrm{~min}$ in inorganic solution (Grohe et al., Langmuir 2009, 25, 11635-11646); ${ }^{\mathrm{E}}$ recent work: precipitated within 30 min in inorganic solution (Grohe et al., Cells Tiss. Org. 2011, 194, 176-181); ${ }^{\mathrm{F}}$ recent work: precipitate within 180 min in ultrafiltered urine (Grohe et al., Urol. Res. 2011, 39, 327-338); ${ }^{\mathrm{G}}$ protein aggregates; ${ }^{\mathrm{H}}$ Urinary trypsin inhibitor (human), N- and O-glycosylated (Kobayashi et al., Kidney Int. 1998, 53, 1727); ${ }^{\mathrm{I}}$ Serum (human) (Thongboonkerd et al., Kidney Int. 2002, 62, 1461); ${ }^{\mathrm{J}}$ urinary (human) (Suzuki et al., Urol. Res. 1994, 22, 45); ${ }^{\mathrm{K}}$ measured value (Malhotra, Biochim. Biophys. Acta 1982, 702, 185); ${ }^{\mathrm{L}}$ bovine, 4 phosphor groups, up to $20 \%$ carbohydrates (Kuebler et al., Biochimie 2007, 89, 410); ${ }^{\mathrm{M}}$ measured

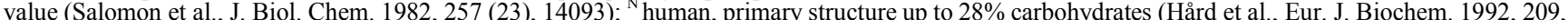
895), for $\mathrm{pI}$ see Schnierle, Experentia 1995, 51, 1068); ${ }^{\circ}$ human, 8 phosphor, 1 sulfate group, O-glycosylated (Christensen et al., Biochem. J. 2008, 411, 53-61); 10 phosphor, 1 sulfate group, O-glycosylated (Keykhosravani et al., Biochemistry 2005, 44, 6990); ${ }^{\mathrm{Q}}$ for pI see Butler, Connect. Tissue Res. 1989, 23,$123 ;{ }^{\mathrm{R}}$ Data from supplier (Invitrogen, Sigma, Worthington Bioch. Corp.).
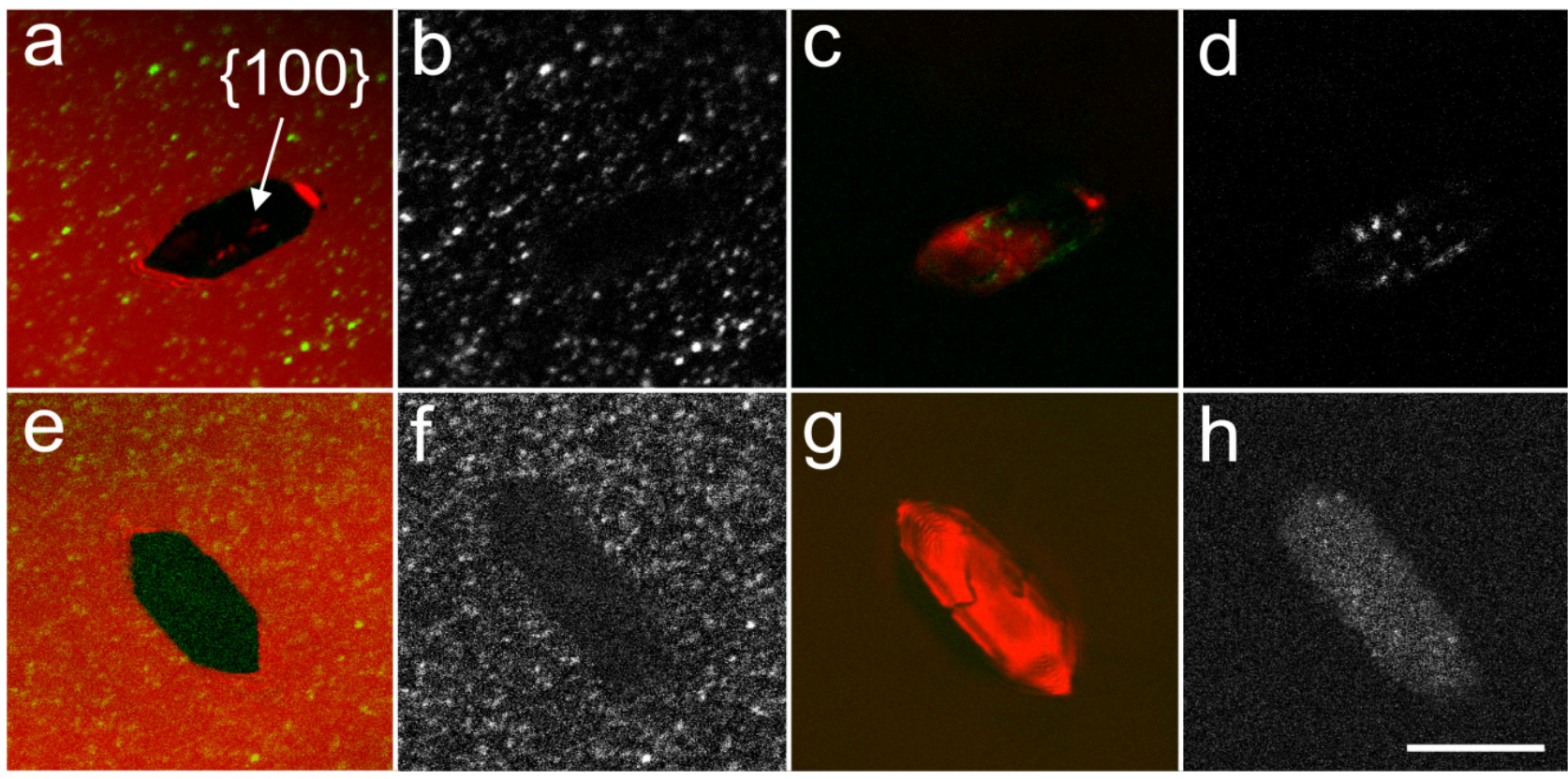

Figure 7. Confocal micrographs of Alexa488-labeled (a-d) THP and (e-h) fetuinA added to pre-grown COM crystals nucleated from $\{100\}$ faces. Panels $(\mathrm{a}, \mathrm{b})$ and $(\mathrm{e}, \mathrm{f})$ are optical sections taken at the crystal-glass interface (bottom of crystal); panels (c,d) and (g,h) are optical sections taken at the crystal-solution interface (top of crystal). Panels a, c, e, and g are combined red (HeNe laser, $\lambda=632.8 \mathrm{~nm}$; illuminated crystal) and green (KrAr laser, $\lambda=488$ $\mathrm{nm}$; illuminated protein) false color images; panels $\mathrm{b}, \mathrm{d}, \mathrm{f}$ and $\mathrm{h}$ are gray scale images (to gain more contrast), converted from the corresponding "green images" in a, c, e, and g, respectively. The scale bar $(9 \mu \mathrm{m})$ in panel $\mathrm{h}$ applies to all panels. Note: the formed aggregates at the glass (b,f) and on top of crystals $(\mathrm{d}, \mathrm{h})$. It appears that the proteins aggregated (perhaps crystalline material incorporated) and then sedimented. 
It is possible, that adsorption processes of near-neutral charged molecules are driven by hydrophilicity and that the hydrophilic character of such a molecule is more crucial for its adsorption behavior than its net negative charge. Indeed, both THP and fetuinA, but also bikunin, have low hydrophilicity values and show aggregation, whereas albumin and PTF1 indicate values at least 3-times higher and form adsorption profiles (see Table 2). Moreover, some studies show that aggregation of THP $[1,45]$ and fetuinA [26] is not unusual (THP can form macroaggregates of several million $\mathrm{Da}$ in urine of healthy individuals [45]) and postulate that this behavior is largely independent from the ingredients of the (urinary or artificial) solution they are part of (not the concentration of ingredients [24]). There is evidence that only in cases of local/temporal high calcium salt concentrations this specific function of THP and fetuinA will be activated (keep crystals small [nucleation rate up], encapsulate them [dispersion rate up], keep them disaggregated [aggregation rate down] and flush them out in the collecting duct), which results in the inhibition of calcification $[1,24,26,30]$. In fact, some findings suggest that THP increases the nucleation rate in urine $[25,46]$ (and it has done so in the present study) and encapsulates the just formed crystallites (nm-rang crystals) delaying their further growth [25,45-46] (unfortunately not to visualize via confocal microscopy) for a comfortable transport through the urinary tract (interestingly, albumin did not have this effect when tested in urine [25]). Thereby, the concentration of THP is believed to determine the ratio of the crystalline mass to be transported, a concentration range perhaps not sufficient in stone formers [24]. FetuinA shows a similar behavior by encapsulating calcium precipitates (incl. in the urinary tract [23]) and is forming colloidal calciprotein particles (30-150 $\mathrm{nm}$ [26]) for particle transport and removal off of mammal's bodies [22,26]. However, the protein is not affecting nucleation; it only inhibits growth of these crystals [26] - a behavior also observed for COM crystals in the present work. There might be effects of the $\mathrm{pH}$ involved in protein-particle-interaction, as investigations show that THP adsorbs to COM crystals at $\mathrm{pH} \geq 7$ [44], while $\mathrm{pH}$ values below 7 (the rule in urine) result in protein-(nascent COM?) aggregates [24]. It might be helpful to analyze highly glycosylated molecules regarding their support of THP or fetuinA (encapsulation, deaggregation, removal of small crystals). Based on our findings, we believe that e.g. low molecular heparin and dextran sulfates are very promising agents to assist these endogenous inhibitors in preventing initial stone formation and/or reducing recurrence rates. As they are already introduced as anticoagulant in e.g. thrombotic disorders [47-48], a relative simple protocol should lead soon to a clear result and to future directions how to clinically proceed.

The strong inhibitors osteopontin and citrate. The precipitation behavior of $\mathrm{CaOx}$ in the presence of OPN and citrate was studied at different additive concentrations and reaction times. Figure 8 shows morphologies and structures of COM crystals and aggregates formed in the presence of OPN. Panels a-e indicate effects of increasing OPN concentrations on COM formation (30 min reaction time), whereas panels $f-j$ show effects of the reaction time on COM formation $(5 \mu \mathrm{g} / \mathrm{ml}$ of OPN added). It is obvious that structures, aggregates and morphologies formed in the presence of $5 \mu \mathrm{g} / \mathrm{ml}$ OPN are independent from reaction times (30 - $1440 \mathrm{~min}$; compare panels d,e with g-j). On the other hand, formation at decreased OPN concentrations $(\leq 2$ $\mu \mathrm{g} / \mathrm{ml}$ ) results in less affected crystal shapes (compare panel $\mathrm{a}, \mathrm{c}$ with $\mathrm{e}$ ), in more spiky aggregates (compare panel b and d) and seemingly fewer aggregates; but an higher overall precipitation rate (compare a and f). In addition, it appears that increasing reaction times lead to slightly larger aggregates when adding $5 \mu \mathrm{g} / \mathrm{ml}$ OPN (compare panels $\mathrm{d}$, g and i). However, Figure 9 (top) indicates that overall precipitation rates of COM (crystals plus aggregates) are significantly higher in the absence of OPN, although both the formation rates of OPN-affected aggregates $(5 \mu \mathrm{g} / \mathrm{ml}$ OPN added) and those of the non-affected aggregates are at a similar level. With respect to aggregate sizes (Figure 9, bottom) an increase over the first period (30-360 min) can be observed for reactions with or without OPN. However, while mean aggregate sizes for controls further increase (> $360 \mathrm{~min}$ ), the protein appears to "protect" COM aggregates from getting larger - a size limiting process also reported for the "core formation" in $\mathrm{CaOx}$ stones [7].

It is important to note that all aggregates found in the present study appear to be hyperstructures mainly generated by multiple twinning and intergrown crystals (see e.g. Figure $8 \mathrm{~b}, \mathrm{~d}, \mathrm{~g}$ ). Analyzing the smaller particles (e.g. Figure 8e,h) clearly shows that there are no clear structures, edges and crystal faces to determine. It is obvious that this kind of aggregate formation excludes - at least in part - the theory that $\mathrm{CaOx}$ aggregates are formed by individual crystals which "stick together in urine" or at cell surfaces to generate larger particles/aggregates [30,49]. Moreover, the OPN-affected aggregates found in this study noticeably resemble core structures of $\mathrm{CaOx}$ stones (see Figure 3).

The findings reported here also confirm earlier observations, indicating that OPN is a strong inhibitor of COM precipitation (nucleation, growth) [14,16,33], but only partly of COM aggregation $[17,33]$. The effects of OPN are based on a relatively high hydrophilicity, which favors its adsorption to COM crystal faces [33,50], and high net negative charges (based on its consecutive row of carboxylates, $\sim 10$ times phosphorylated) resulting in a strong binding (chemisorption) of the protein to calcium dense and positively charged crystal faces [14,32,37-38]. The latter part-process leads to the partial blockage of calcium and oxalate ion incorporation into COM crystal lattices and, thus, to an inhibition of crystal growth [14,39-40]; but also to an ongoing incorporation of the protein into the crystal matrix $[13,15]$. It is assumed that these mechanisms finally result in the intergrowth of crystals, a process which forms larger masses with time and contributes to a relatively unhindered formation of aggregates (Figure 8 and 9 top). Moreover, as 
the system accepts growth rather than formation of further aggregates (see Figure 9, bottom; maybe the surface energy of a few larger aggregates can be lowered more readily than the surface energy of multiple smaller aggregates [51,52]) nature appears to protect the body by concentrating ectopic calcification to a few spots [2], preventing the formation of multiple stones in the entire upper urinary tract (except in cases of e.g. primary hyperoxalosis [8]).

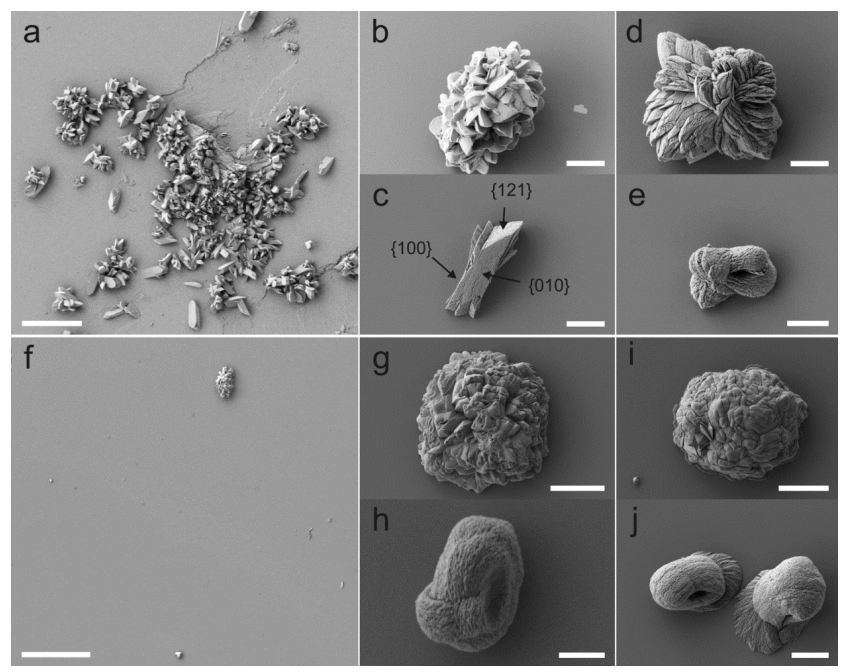

Figure 8. SEM micrographs of COM crystals and aggregates formed in the presence of varying OPN concentrations $(1-5 \mu \mathrm{g} / \mathrm{ml})$ and at different reaction times $\left(30-1440 \mathrm{~min} ;\left[\mathrm{Ca}^{2+}\right]=\left[\mathrm{C}_{2} \mathrm{O}_{4}{ }^{2-}\right]=1 \mathrm{mM}\right)$. Panels a - e: COM formed for $30 \mathrm{~min}$ in the presence of (a) $1 \mu \mathrm{g} / \mathrm{ml}$, (b,c) $2 \mu \mathrm{g} / \mathrm{ml}$ and (d,e) $5 \mu \mathrm{g} / \mathrm{ml}$ OPN. Panels $\mathrm{f}-\mathrm{j}$ : COM formed in the presence of $5 \mu \mathrm{g} / \mathrm{ml}$ OPN for (f-h) $120 \mathrm{~min}$ and (i,j) for $1440 \mathrm{~min}$. The scale bars in a, b, c, d, e, f, $\mathrm{g}, \mathrm{h}, \mathrm{i}, \mathrm{j}$ are $20,5,3,2,2,40,15,1,20$ and $2 \mu \mathrm{m}$, respectively.

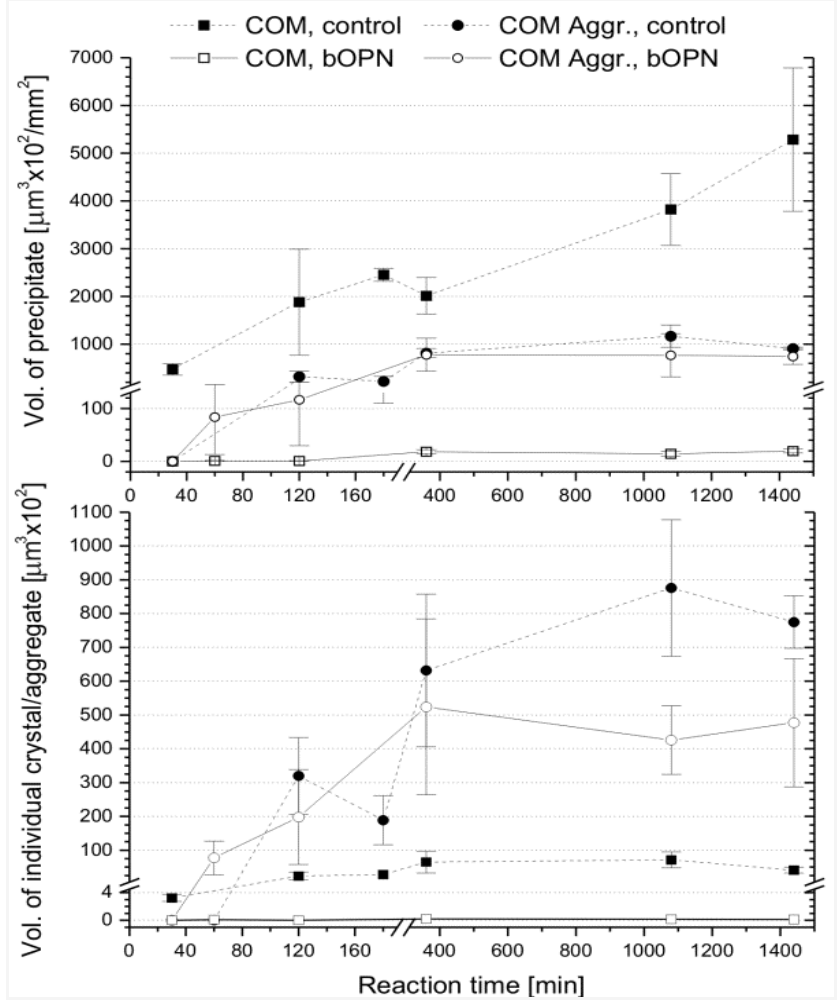

Figure 9. Formation of COM crystals and aggregates in the presence and absence of $5 \mu \mathrm{g} / \mathrm{ml} \mathrm{OPN}\left(\left[\mathrm{Ca}^{2+}\right]=\left[\mathrm{C}_{2} \mathrm{O}_{4}{ }^{2-}\right]=1 \mathrm{mM}\right)$. Top: volume of total precipitated COM. Bottom: volume of individual crystal/aggregate.

Similar to OPN, the low molecular weight compound citrate only slightly contributes to an inhibition of aggregate formation (Figure 10). In fact, citrate hinders COM to nucleate and grow (affected by molecule-crystal interaction $[17,20]$; see also introduction), but the aggregates found are large and appear to be formed by individual crystals, which stuck together and then fused after some time of COM precipitation. In other words, these large aggregates are formed with time (reaction time $>180 \mathrm{~min}$ ) - shorter reaction times did not generate large aggregates [17,20]. The shapes and structures of these aggregates are less compact and "stone-like" as the masses formed at e.g. $5 \mu \mathrm{g} / \mathrm{ml}$ OPN (compare Figure 10 with 8). In addition, the crystals constituting these aggregates are flat and smooth and show strong similarities to those occasionally found in/near the core-mantle-interface region (see Figure 3) and those forming the layered structures in the mantle region of stones (see e.g. Fig 4). However, with respect to the latter, there are two main differences: 1. our crystals are much shorter (direction parallel to $<001>$ ) and 2., unlike in the mantle region, the crystals synthesized here are not nucleating and growing on each other's $\{100\}$ faces. In addition, even the order level of crystals formed at stone surfaces is not reached by our in vitro grown crystals (compare Figure 10 with 4a-c). Nevertheless, the fact that citrate and not OPN or any other protein or GAG has - to our knowledge - the potency to form these COM crystal shapes (see literature for e.g. OPN $[14,16,18]$, FeA [26], THP [33,46], and GAGs [28]) provides a possibility for a hypothesis on how stone formation might be affected by citrate (see next section, 3.3).

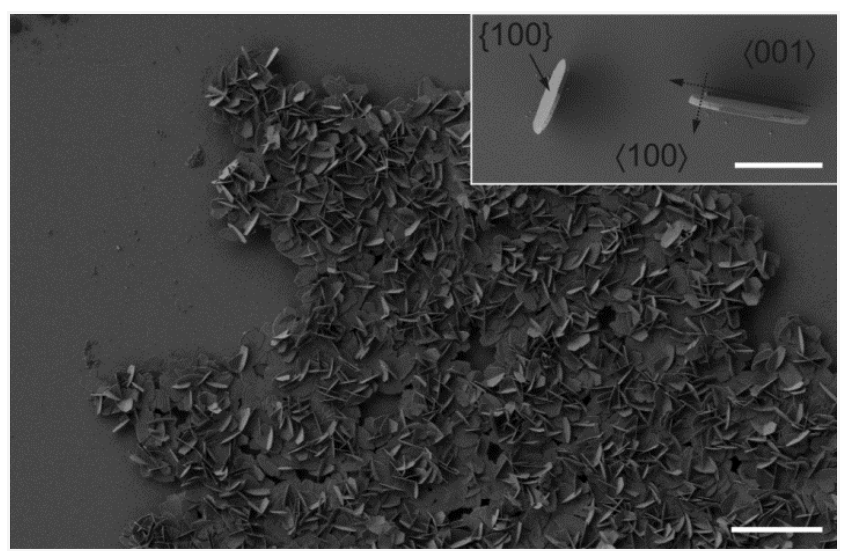

Figure 10. SEM micrographs of COM crystals and aggregates formed in the presence of $250 \mu \mathrm{M}$ citrate (reaction time: $180 \mathrm{~min}$ ). Scale bar: $10 \mu \mathrm{m}$ (Inset; scale bar: $4 \mu \mathrm{m}$ ).

\subsection{Correlation of in Vitro Formed and Polyelectrolyte - affected COM Morphologies with in Vivo Generated Structures of Papillary Stones Section}

The inner regions of stones: the morphology and structure of the core as a result of multiple organic-inorganic-interactions. Starting on the nidus (nidus: COM-CaP plaques [Randal's plaque] attached to the 
injured epithelium and surrounded/covered by membranes, lipids, vesicles, cellular debris acting as crystal nucleators [1-2]), the core forms by generating loose complex and spatial structures of mostly very fragile twinned and intergrown crystal systems (see Figure 3 and 5a,d,e). These crystals form within an organic matrix and exhibit donut-, dumbbell- and short range layered structures (Figure 3a-c). But also some coarser structures and aggregated platelets (partly coated by organic debris) can be found (Figure 3d,e). These structures and morphologies are very similar to those found when $\mathrm{COM}$ was in vitro grown, in the presence of OPN (Figure 8; for stone sections see also $[16,18]$ ). Therefore, OPN concentrations are proposed to be high enough to compete with e.g. citrate in affecting COM growth. Particularly those structures grown in the presence of 5 $\mu \mathrm{g} / \mathrm{ml}$ OPN (near the physiological concentration of $\sim 4.5$ $\mu \mathrm{g} / \mathrm{ml}[53]$ ) have strong similarities with the structures found in the core of stones (compare e.g. Figure 8d,e,h-j with Figure 3a-d). However, OPN is not the only protein and molecule present, sufficient in affecting early stone formation [1]. It has been shown that THP and albumin are part of the organic matrix of the nidus $[2,10]$. But, while THP was either present in the core (not in plaque! [2]) or not detected at all [10] (perhaps transporting dispersed crystals in the collecting duct), albumin was an abundant component [10]. Similarly, while fetuinA revealed no sign of protein incorporation into stone matrices [18], bikunin, Inter- $\alpha$-trypsin and PTF1 were incorporated into stones and urinary crystals $[1,54]$. But all of these proteins, including THP and albumin, indicated no effect on COM morphologies [1], a finding also reported for in vitro studies [33] (see also Table 2). In contrast, the GAG heparan sulfate has been reported to be involved in stone formation [27-28]. It generates distinctive dumbbell shapes (like OPN) [55] and affects the formation of the core at high physiological concentrations $(\sim 10 \mu \mathrm{g} / \mathrm{ml})[29,55]$. On the other hand, its presence in stones is only marginal [27].Citrate is expected to be involved in the formation of the core, as well. But there are only a few signs of its possible presence in the core (see platelets Figure 3d,e, compare with Figure 10) [7]. Other urinary compounds such as magnesium, pyrophosphate, phosphates, lipids and cellular fragments are not reported to show specific effects on crystal or stone morphologies [1]. After all, there is strong evidence that OPN is the main component in affecting crystal formation of the core. Citrate, peptides, heparan sulfate and hyper concentrations of weak interacting macromolecules/cell fragments might contribute in altering crystal morphologies. However, this is not to identify using the methods of the present work.

The inner regions of stones - the core/mantle interface; its structural components indicate an increased influence of citrate as an inhibitor. The morphology of the core/mantle interface (Figure 3a) exhibits neither the ordered and layered structures of the mantle/surface region (Figure $4 \mathrm{a}-\mathrm{c})$ nor the loose complex spatial structures of the core (Figure 3). It is a region, in which the mechanisms responsible for the formation of the core change. This change creates an environment for crystallization processes, which result in the generation of highly compacted platelets, twins and twin superstructures. Near to the mantle region columnar crystals form and initiate the development of the stone's striated mantle layer (see also Soehnel et al. [5]).

Although it is poorly understood what mechanisms lead to these changes in growth conditions, the structure of this transitional phase indicates some signs that molecule-crystal interactions are increasingly dominated by citrate or effectors which - like citrate - preferentially affect the $\{100\}$ faces of COM crystals (compare Figure 3a,b (top-left) with Figure 10). Moreover, the crystal morphologies in this region suggest decreased overall polyelectrolyte concentration ranges of e.g. OPN and other effectors. A hint for this assumption is also given in Table 1 (the mantle contains by far less organics than the core). In addition, for the weak effector THP, Coe et al. [2] have indeed shown that the protein can be part of the core; but (to our knowledge) there is no data available reporting the presence of THP within the mantle or surface region of $\mathrm{CaOx}$ stones. With respect to OPN, McKee et al. [18] found that its number density is highest in the core and gets gradually lower towards the mantle region, an outcome that is supported by our morphological study.

The outer region of stones - the mantle and surface region; the morphologies and structures suggest an environment which promotes oriented growth. The dominance of plate-like crystals in the mantle and surface regions of stones is obvious (Figure 4). Therefore, OPN concentrations are assumed to be not high enough to compete with e.g. citrate in affecting COM growth during mantle formation. Indeed, Kohri and McKee et al. [16,18] have found that the distribution of OPN in the peripheral mantle shows only patches of locally high concentrations (e.g. in close proximity to Randall's plaque or within so-called "organic troughs", see Figure 5 and Table 1; see also Coe et al. [2]) or concentric rings, both within large regions of low/no OPN densities. But these areas showed no sign of OPN-affected COM morphologies (e.g. dumbbells; see also Figure 4a,b and compare with Figure 8e,h,j). In addition, it has been reported that the entire outer surface of these stones appears to be "OPN-free" with a few cases of OPN coverage [16,18], suggesting processes based on biological cycles [9]. Likewise heparan sulfate; the concentration of this molecule (like that of OPN) appears to be not reaching the levels to compete with e.g. citrate in affecting COM morphologies - otherwise dumbbell shapes would have been found in the mantle and surface region of stones (see also Michelacci and Shirane et al. [29,55]). The only GAG which could form flat crystals like citrate is heparin (see Figure 6f; all other GAGs [e.g. hyaluronic acid, chondroitin sulfate] are not potent enough to alter crystal shapes significantly $[28,55])$. Although heparin is not a common part of the urinary tract [31] (note: dextran sulfate tested here is not part of the physiology at all [47]), it might be possible that heparin enters the urinary tract under some circumstances (perhaps in the course of an ongoing therapy) 
and acts then as inhibitor of COM formation $[31,56]$. But this is still unclear. Another class of organic components that are sometimes overlooked is the category of peptides and organic fragments. For instance, Cutillas et al. [57] have recently detected peptides of over 100 different species in urine samples; a part of these peptides is acidic and some of them have shown their capacity as inhibitor [58]. Moreover, it was found that the formation of COM in the presence of 5 $\mu \mathrm{g} / \mathrm{ml}$ highly carboxylated (but not: carboxylated + phosphorylated, or only phosphorylated) synthetic OPN peptides results in platelet-shaped crystals very similar to those formed when citrate is present. These platelets, which grow in alignment and generating highly structured aggregates, contain domains, where $\{100\}$ faces of the platelets face each other (see Figure 11; A.A., B.G. and G.K. Hunter, unpublished data).

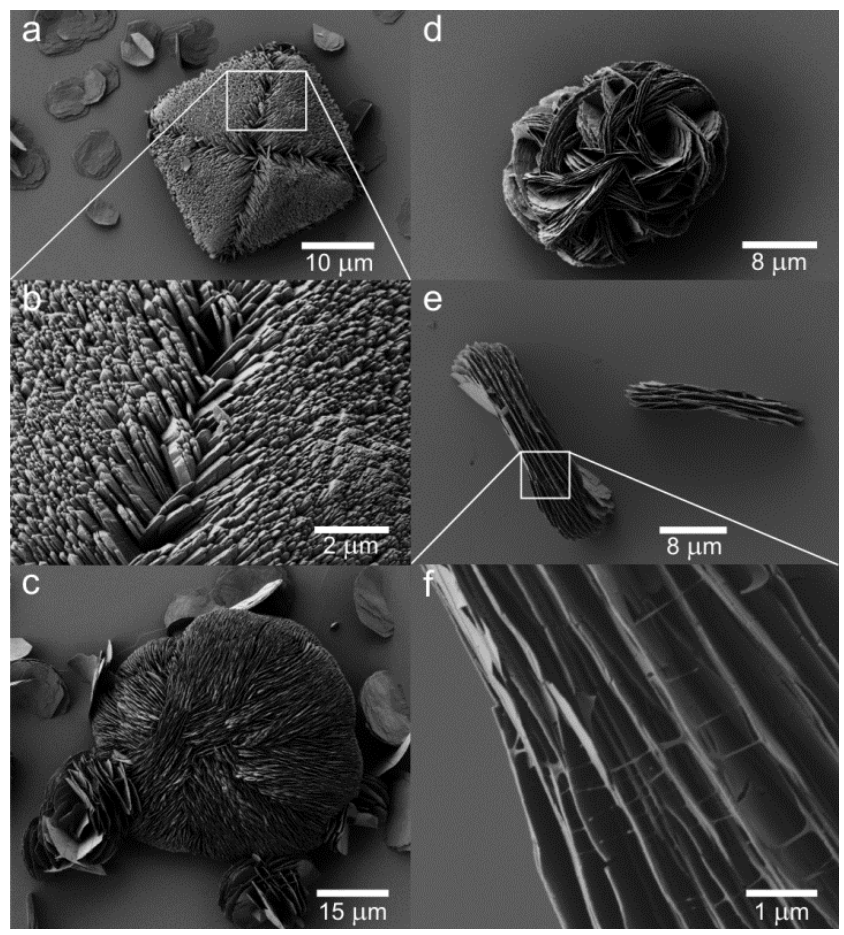

Figure 11. Scanning electron micrographs of COM crystals and aggregates that formed during different reaction times $\left(60-1440 \mathrm{~min} ; 37^{\circ} \mathrm{C}\right.$; $\left[\mathrm{Ca}^{2+}\right]=\left[\mathrm{C}_{2} \mathrm{O}_{4}{ }^{2-}\right]=1 \mathrm{mM}$ ) and in the presence of $5 \mu \mathrm{g} / \mathrm{ml}$ highly carboxylated peptides corresponding to residues $65-80$ of rat OPN. The peptides contain a consecutive aspartic acid sequence and were synthesized (Fmoc chemistry [for synthesize see e.g. Hug et al. [39]) in both a phosphorylated (pSHDHMDDDDDDDDDGD; referred to as pOPAR) and a non-phosphorylated (SHDHMDDDDDDDDDGD; OPAR) form. Panels a - c: COM formed in the presence of OPAR for (a,b) 60 min and (c) for 1080 min. Panels d - f: COM formed in the presence of pOPAR for (d) $360 \mathrm{~min}$ and (e,f) for $1440 \mathrm{~min}$. Note: highly ordered structures and crystal alignments are formed in the presence of OPAR (panel a $-\mathrm{c}$ ). Phosphorylation instead appears to act as an adhesive and to "glue" the individual crystal platelets together $(\mathrm{d}-\mathrm{f})$, forming aggregates with less ordered structures (d).

These structures were only found after longer reaction times ( $\geq 60 \mathrm{~min}$ ). It is suggested that the nature of these peptides promotes a self assembly process when the system is approaching the equilibrium, creating a more ordered state of the platelets and reducing the free energy further [59-60]. In addition, it appears that phosphorylation of these peptides results in the "gluing" of platelets preventing the formation of an aligned platelet structure (Figure 11d-f; individual sheets are anchored with no chance of re-arrangement), but promoting COM structures very similar to those found in the core of stones (Figure 3a-c) or the COM morphologies grown in the presence of OPN (Figure 8; OPN: also carboxylated + phosphorylated).

Taking all these aspects into account, citrate might be the main component in affecting the mantle and surface formation of $\mathrm{CaOx}$ stones. However, some protein/GAG fragments, and perhaps heparin (if present) could be essential factors in mantle-related biomolecule-crystal interactions and aggregate formation. Finally, we have focused here on those biomolecules that can (a) cause effects on COM morphologies at physiological concentrations and (b) the correlation of the altered crystal morphologies (via in vitro experiments) to those found in $\mathrm{CaOx}$ stone formation. A more general consideration of stone forming processes is beyond the objective of the study.

\section{Conclusions}

Sections of idiopathic calcium oxalate kidney stones (the core, the core/mantle interface, the mantle and outer surfaces) were investigated and the stone-constituting crystal morphologies compared with in vitro-mineralized COM. The in vitro studies showed that longtime crystallization in the presence of OPN results in complex COM aggregates very similar to those found in the core of stones, whereas crystal morphologies formed in the presence of citrate closely resemble crystal shapes found in the core/mantle interface and the mantle region. However, the experiments could not clarify how the columnar platelets grow and align forming the well ordered structures found in the mantle. It is suggested that variations in OPN and citrate concentrations as well as changed thermodynamic conditions lead to these well ordered structures, not the absence of one or the other molecule. Other acidic effectors, perhaps peptides, might be involved in these processes, as well. Studying the highly negatively charged polysaccharides heparin and dextran sulfate indicated their ability to assist THP or fetuinA in preventing crystal aggregate formation (thus supporting excretion). Moreover, in contrast to urinary GAGs, the formation of $\mathrm{CaOx}$ was inhibited significantly by those molecules, suggesting that heparin and dextran sulfate could also help OPN and citrate in COM inhibition processes.

\section{Acknowledgements}

The authors thank Todd Simpson (Nanofabrication Facility, Department of Science, University of Western Ontario [UWO]) for assistance with electron microscopy/energy dispersive analysis, Steven Sims 
(Department of Physiology \& Pharmacology, UWO) for providing the Nikon microscopy setup, Kem Rogers (Department of Anatomy and Cell Biology, UWO) for help in confocal microscopy and Willi Jahnen-Dechent (Technical University of Aachen, Germany) for valuable reagents. The expert technical assistance of Kari Ann Orlay and Honghong Chen (Department of Dentistry and Physiology \& Pharmacology, UWO) is gratefully acknowledged. We thank Silvia Mittler (Department of Physics and Astronomy, UWO) for many helpful discussions. We are Graeme Hunter and Harvey Goldberg (School of Dentistry and Department of Biochemistry, UWO) very grateful for financial support and for many stimulating discussions.

\section{REFERENCES}

[1] Khan, S. R.; Kok, D. J. Modulators of urinary stone formation. Frontiers in Bioscience, 9: 1450-1482, 2004.

[2] Coe, F. L.; Evan, A. P.; Worcester, E. M.; Lingeman, J. E. Three pathways for human kidney stone formation. Urological Research, 38(3): 147-160, 2010.

[3] Evan, A. P.; Lingeman, J. E.; Coe, F. L.; Parks, J. H.; Bledsoe, S. B.; Shao, Y. Z.; Sommer, A. J.; Paterson, R. F.; Kuo, R. L.; Grynpas, M. Randall's plaque of patients with nephrolithiasis begins in basement membranes of thin loops of Henle. Journal of Clinical Investigation, 111(5): 607-616, 2003.

[4] Sethmann, I.; Grohe, B.; Kleebe, H. J. Replacement of hydroxylapatite by whewellite: implications for kidney-stone formation. Mineralogical Magazine, 78(1): 91-100, 2014.

[5] Sohnel, O.; Grases, F. Calcium-Oxalate Monohydrate Renal Calculi - Formation and Development Mechanism. Advances in Colloid and Interface Science, 59: 1-17, 1995.

[6] Khan, S. R.; Hackett, R. L. Role of Organic Matrix in Urinary Stone Formation - an Ultrastructural-Study of Crystal Matrix Interface of Calcium-Oxalate Monohydrate Stones. Journal of Urology, 150(1): 239-245, 1993.

[7] Grases, F.; Costa-Bauza, A.; Garcia-Ferragut, L. Biopathological crystallization: a general view about the mechanisms of renal stone formation. Advances in Colloid and Interface Science, 74: 169-194, 1998.

[8] Jacob, D. E.; Grohe, B.; Gessner, M.; Beck, B. B.; Hoppe, B. Kidney Stones in Primary Hyperoxaluria: New Lessons Learnt. Plos One, 8(8): e70617, 2013.

[9] Al-Atar, U.; Bokov, A. A.; Marshall, D.; Teichman, J. M. H.; Gates, B. D.; Ye, Z. G.; Branda, N. R. Mechanism of Calcium Oxalate Monohydrate Kidney Stones Formation: Layered Spherulitic Growth. Chemistry of Materials, 22(4): 1318-1329, 2010.

[10] Dussol, B.; Geider, S.; Lilova, A.; Leonetti, F.; Dupuy, P.; Daudon, M.; Berland, Y.; Dagorn, J. C.; Verdier, J. M. Analysis of the Soluble Organic Matrix of 5 Morphologically Different Kidney-Stones - Evidence for a Specific Role of Albumin in the Constitution of the Stone Protein Matrix. Urological Research, 23(1): 45-51, 1995.
[11] Wesson, J. A.; Worcester, E. M.; Wiessner, J. H.; Mandel, N. S.; Kleinman, J. G. Control of calcium oxalate crystal structure and cell adherence by urinary macromolecules. Kidney International, 53(4): 952-957, 1998.

[12] Hunter, G. K.; O’Young, J.; Grohe, B.; Karttunen, M.; Goldberg, H. A. The Flexible Polyelectrolyte Hypothesis of Protein-Biomineral Interaction; Feature Article. Langmuir, 26(24): 18639-18646, 2010.

[13] Hunter, G. K.; Grohe, B.; Jeffrey, S.; O’Young, J.; Sørensen, E. S.; Goldberg, H. A. Role of Phosphate Groups in Inhibition of Calcium Oxalate Crystal Growth by Osteopontin. Cells, Tissues, Organs, 189(1-4): 44-50, 2009.

[14] Langdon, A.; Wignall, G. R.; Rogers, K. A.; Sørensen, E. S.; Denstedt, J.; Grohe, B.; Goldberg, H. A.; Hunter, G. K. Kinetics of Calcium Oxalate Crystal Growth in the Presence of Osteopontin Isoforms: An Analysis by Scanning Confocal Interference Microcopy. Calcified Tissue International, 84: 240-248, 2009.

[15] Thurgood, L. A.; Cook, A. F.; Sorensen, E. S.; Ryall, R. L. Face-specific incorporation of osteopontin into urinary and inorganic calcium oxalate monohydrate and dihydrate crystals. Urological Research, 38(5): 357-376, 2010.

[16] Kohri, K.; Yasui, T.; Okada, A.; Hirose, M.; Hamamoto, S.; Fujii, Y.; Niimi, K.; Taguchi, K. Biomolecular mechanism of urinary stone formation involving osteopontin. Urological Research, 40(6): 623-637, 2012.

[17] Grohe, B.; Chan, B. P. H.; Sørensen, E. S.; Lajoie, G.; Goldberg, H. A.; Hunter, G. K. Cooperation of phosphates and carboxylates controls calcium oxalate crystallization in ultrafiltered urine. Urological Research, 39: 327-338, 2011.

[18] McKee, M. D.; Nanci, A.; Khan, S. R. Ultrastructural Immunodetection of Osteopontin and Osteocalcin as Major Matrix Components of Renal Calculi. Journal of Bone and Mineral Research, 10(12): 1913-1929, 1995.

[19] Hallson, P. C.; Rose, G. A.; Sulaiman, S. Raising Urinary Citrate Lowers Calcium-Oxalate and Calcium-Phosphate Crystal-Formation in Whole Urine. Urologia Internationalis, 38(3): 179-181, 1983.

[20] Grohe, B.; O’Young, J.; Langdon, A.; Karttunen, M.; Goldberg, H. A.; Hunter, G. K. Citrate Modulates Calcium Oxalate Crystal Growth by Face-Specific Interactions. Cells Tissues Organs, 194(2-4): 176-181, 2011.

[21] Van Rooijen, J. J. M.; Voskamp, A. F.; Kamerling, J. P.; Vliegenthart, J. F. G. Glycosylation sites and site-specific glycosylation in human Tamm-Horsfall glycoprotein. Glycobiology, 9(1): 21-30, 1999.

[22] Jahnen-Dechent, W.; Heiss, A.; Schafer, C.; Ketteler, M. Fetuin-A Regulation of Calcified Matrix Metabolism. Circulation Research, 108(12): 1494-1509, 2011.

[23] Wu, Y. X.; Li, C. Y.; Deng, Y. L. Patients with nephrolithiasis had lower fetuin-A protein level in urine and renal tissue. Urolithiasis, 42(1): 29-37, 2014.

[24] Hess, B. Tamm-Horsfall Glycoprotein - Inhibitor or Promoter of Calcium-Oxalate Monohydrate Crystallization Processes. Urological Research, 20(1): 83-86, 1992. 
[25] Rose, G. A.; Sulaiman, S. Tamm-Horsfall Mucoproteins Promote Calcium-Oxalate Crystal-Formation in Urine Quantitative Studies. Journal of Urology, 127(1): 177-179, 1982.

[26] Heiss, A.; DuChesne, A.; Denecke, B.; Grotzinger, J.; Yamamoto, K.; Renne, T.; Jahnen-Dechent, W. Structural basis of calcification inhibition by alpha(2)-HS glycoprotein/fetuin-A - Formation of colloidal calciprotein particles. Journal of Biological Chemistry, 278(15): 13333-13341, 2003.

[27] Yoshimura, K.; Yoshioka, T.; Miyake, O.; Honda, M.; Yamaguchi, S.; Koide, T.; Okuyama, A. Glycosaminoglycans in crystal-surface binding substances and their role in calcium oxalate crystal growth. British Journal of Urology, 80(1): 64-68, 1997.

[28] Suzuki, K.; Mayne, K.; Doyle, I. R.; Ryall, R. L. Urinary Glycosaminoglycans Are Selectively Included into Calcium-Oxalate Crystals Precipitated from Whole Human Urine. Scanning Microscopy, 8(3): 523-530, 1994

[29] Michelacci, Y. M.; Glashan, R. Q.; Schor, N. Urinary-Excretion of Glycosaminoglycans in Normal and Stone Forming Subjects. Kidney International, 36(6): 1022-1028, 1989.

[30] Lieske, J. C.; Toback, F. G. Renal cell-urinary crystal interactions. Current Opinion in Nephrology and Hypertension, 9(4): 349-355, 2000.

[31] Triplett, D. A. Heparin - Biochemistry, Therapy, and Laboratory Monitoring. Therapeutic Drug Monitoring, 1(2): 173-197, 1979.

[32] Taller, A.; Grohe, B.; Rogers, K. A.; Goldberg, H. A.; Hunter, G. K. Specific adsorption of osteopontin and synthetic polypeptides to calcium oxalate monohydrate crystals. Biophysical Journal, 93(5): 1768-1777, 2007.

[33] Grohe, B.; Taller, A.; Vincent, P. L.; Tieu, L. D.; Rogers, K. A.; Heiss, A.; Sorensen, E. S.; Mittler, S.; Goldberg, H. A.; Hunter, G. K. Crystallization of Calcium Oxalates Is Controlled by Molecular Hydrophilicity and Specific Polyanion-Crystal Interactions. Langmuir, 25(19): 11635-11646, 2009.

[34] Bader, C. A.; Chevalier, A.; Hennequin, C.; Jungers, P.; and Daudon, M. Methodological aspects of spontaneous crystalluria studies in calcium stone formers. Scanning Microscopy, 8(2): 215-232, 1994.

[35] Lloyd, G. E. Atomic-Number and Crystallographic Contrast Images with the Sem - a Review of Backscattered Electron Techniques. Mineralogical Magazine, 51(359): 3-19, 1987.

[36] Cheng, P. T.; Reid, A. D.; Pritzker, K. P. H. Ultrastructural Studies of Crystal-Organic Matrix Relations in Renal Stones. Scanning Electron Microscopy, (Pt 1): 201-207, 1985.

[37] Fernandez, J. C.; Delasnieves, F. J.; Salcedo, J. S.; Hidalgoalvarez, R. The Microelectrophoretic Mobility and Colloid Stability of Calcium-Oxalate Monohydrate Dispersions in Aqueous-Media. Journal of Colloid and Interface Science, 135(1): 154-164, 1990.

[38] Jung, T.; Sheng, X. X.; Choi, C. K.; Kim, W. S.; Wesson, J. A.; Ward, M. D. Probing crystallization of calcium oxalate monohydrate and the role of macromolecule additives with in situ atomic force microscopy. Langmuir, 20(20): 8587-8596,
2004.

[39] Hug, S.; Grohe, B.; Jalkanen, J.; Chan, B. P. H.; Galarreta, B.; Vincent, K.; Lagugné-Labarthet, F.; Lajoie, G.; Goldberg, H. A.; Karttunen, M.; and Hunter, G. K. Mechanism of Inhibition of Calcium Oxalate Crystal Growth by an Osteopontin Phosphopeptide. Soft Matter, 8: 1226-1233, 2012.

[40] Grohe, B.; Hug, S.; Langdon, A.; Jalkanen, J.; Rogers, K. A.; Goldberg, H. A.; Karttunen, M.; Hunter, G. K. Mimicking the Biomolecular Control of Calcium Oxalate Monohydrate Crystal Growth: Effect of Contiguous Glutamic Acids. Langmuir, 28(33): 12182-12190, 2012.

[41] O’Young, J. C., S.; Al Tarhuni, N.; Grohe, B.; Karttunen, M.; Goldberg, H. A.; Hunter, G. K. Phosphorylation of Osteopontin Peptides Mediates Adsorption to and Incorporation into Calcium Oxalate Crystals. Cell, Tissues, Organs, 189(1-4): 51-55, 2009.

[42] Chan, B. P. H.; Vincent, K.; Lajoie, G. A.; Goldberg, H. A.; Grohe, B.; Hunter, G. K. On the catalysis of calcium oxalate dihydrate formation by osteopontin peptides. Colloids and Surfaces B-Biointerfaces, 96: 22-28, 2012.

[43] Hess, B.; Jaggi, M.; Zipperle, L.; Jaeger, P. Reduced Carbohydrate Content of Tamm-Horsfall Glycoprotein (Thp) from Severely Recurrent Renal Calcium Stone Formers (Rcsf). Journal of the American Society of Nephrology, 6(3): 949-952, 1995.

[44] Viswanathan, P.; Rimer, J. D.; Kolbach, A. M.; Ward, M. D.; Kleinman, J. G.; Wesson, J. A. Calcium oxalate monohydrate aggregation induced by aggregation of desialylated Tamm-Horsfall protein. Urological Research, 39(4): 269-282, 2011.

[45] Lau, W. H.; Leong, W. S.; Ismail, Z.; Gam, L. H. Qualification and application of an ELISA for the determination of Tamm Horsfall Protein (THP) in human urine and its use for screening of Kidney Stone Disease. International Journal of Biological Sciences, 4(4): 215-222, 2008.

[46] Carvalho, M.; Mulinari, R. A.; Nakagawa, Y. Role of Tamm-Horsfall protein and uromodulin in calcium oxalate crystallization. Brazilian Journal of Medical and Biological Research, 35(10): 1165-1172, 2002.

[47] Hall, M.; Ricketts, C. R. The Use of Dextran Sulphate as a Blood Anticoagulant in Biological Research. Journal of Clinical Pathology, 5(4): 366-366, 1952.

[48] Laposata, M.; Green, D.; Van Cott, E. M.; Barrowcliffe, T. W.; Goodnight, S. H.; Sosolik, R. C. College of American Pathologists Conference XXXI on Laboratory Monitoring of Anticoagulant Therapy - The clinical use and laboratory monitoring of low-molecular-weight heparin, danaparoid, hirudin and related compounds, and argatroban. Archives of Pathology \& Laboratory Medicine, 122(9): 799-807, 1998.

[49] Basavaraj, D. R.; Biyani, C. S.; Browning, A. J.; Cartledge, J. J. The Role of Urinary Kidney Stone Inhibitors and Promoters in the Pathogenesis of Calcium Containing Renal Stones. EAU-EBU Update Series (European Association of Urology), 5: 126-136, 2007.

[50] Kazemi-Zanjani, N.; Chen, H. H.; Goldberg, H. A.; Hunter, G. K.; Grohe, B.; Lagugne-Labarthet, F. Label-Free Mapping of Osteopontin Adsorption to Calcium Oxalate Monohydrate 
Crystals by Tip-Enhanced Raman Spectroscopy. Journal of the American Chemical Society, 134(41): 17076-17082, 2012.

[51] Carter, C. B.; Norton, M. G. Ceramic materials science and engineering. 2nd ed.; Springer: New York, NY, 2013.

[52] Grohe, B.; Miehe, G.; Wegner, G. Additive controlled crystallization of barium titanate powders and their application for thin-film ceramic production: Part I. Powder Synthesis. Journal of Materials Research, 16(7): 1901-1910, 2001.

[53] Min, W.; Shiraga, H.; Chalko, C.; Goldfarb, S.; Krishna, G. G.; Hoyer, J. R. Quantitative studies of human urinary excretion of uropontin. Kidney International, 53(1): 189-193, 1998.

[54] Cook, A. F.; Grover, P. K.; Ryall, R. L. Face-specific binding of prothrombin fragment 1 and human serum albumin to inorganic and urinary calcium oxalate monohydrate crystals. Bju International, 103(6): 826-835, 2009.

[55] Shirane, Y.; Hamao, T.; Kagawa, S. The effect of glycosaminoglycans on calcium oxalate crystal formation. The Japanese Journal of Urology, 81(7): 1065-1070, 1990.
[56] Ablove, T.; Patankar, M.; Seo, S. Prevention of recurrent urinary tract infections by intravesical administration of heparin: a pilot study. Therapeutic Advances in Urology, 5(6): 303-309, 2013.

[57] Cutillas, P. R.; Norden, A. G. W.; Cramer, R.; Burlingame, A. L.; Unwin, R. J. Detection and analysis of urinary peptides by on-line liquid chromatography and mass spectrometry: application to patients with renal Fanconi syndrome. Clinical Science, 104(5): 483-490, 2003.

[58] Ito, H.; Coe, F. L. Acidic Peptide and Polyribonucleotide Crystal-Growth Inhibitors in Human Urine. American Journal of Physiology, 233(5): F455-F463, 1977.

[59] Whitesides, G. M.; Boncheva, M. Beyond molecules: Self-assembly of mesoscopic and macroscopic components. Proceedings of the National Academy of Sciences of the United States of America, 99(8): 4769-4774, 2002.

[60] Blanazs, A.; Armes, S. P.; Ryan, A. J. Self-Assembled Block Copolymer Aggregates: From Micelles to Vesicles and their Biological Applications. Macromolecular Rapid Communications, 30(4-5): 267-277, 2009 